December 11, 2008

\title{
Investment Model Uncertainty and Fair Pricing
}

\begin{abstract}
Modern investment theory takes it for granted that a Security Market Line (SML) is as certain as its "corresponding" Capital Market Line. (CML). It can be easily demonstrated that this is not the case. Knightian non-probabilistic, information gap uncertainty exists in the security markets, as the bivariate "Galton's Error" of unilateral projection betas and its concomitant information gap proves. The existing information gap requires that an SML graph needs (at least) two parallel horizontal beta axes, and not the one unilaterally projected beta axis. This implies that a particular mean security return corresponds with a limited Knightian uncertainty range of betas, although it does correspond with only one market portfolio risk volatility. This implies also that a security risk premium is uncertain and that a Knightian uncertainty range of SMLs and of fair pricing exists. This Knightian uncertainty spread and corresponding premium measures how much confidence an investor can have in an investment model. This paper both updates my 1999 empirical evidence to 2007 and it graphically traces the financial market consequences of this model uncertainty for modern investment theory. First, any investment knowledge about securities' risk remains uncertain. Investment valuations carry with them epistemological ("modeling") risk in addition to the Markowitz-Sharpe market risk, as measured by Keynesian risk measures. Second, since idiosyncratic, or firm-specific, risk is limited-uncertain, the real option value of a firm is also limited-uncertain. This explains the simultaneous coexistence of different analyst valuations of investment projects, particular firms or industries, included the category "undecided." Third, we can distinguish between "buy", "sell" and "hold" trading orders based on an empirically determined collection of SMLs, based this Knightian modeling risk. The coexistence of such simultaneous value signals for the same security provides the liquidity spread necessary for the existence of a market for that security! Without epistemological investment uncertainty, no ongoing market-making for securities could exist. In the absence of transaction costs and other inefficiencies, Knightian uncertainty provides the necessary energy for market trading, since it creates potential or perceived arbitrage (= trading) opportunities. It is also necessary for investors to hold securities. Knightian uncertainty provides a possible reason why the SEC can't obtain consensus on what constitutes "fair pricing." The paper also shows that Malkiel's recommended CML-based investments are extremely conservative and non-robust.

Key Words: capital market line, security market line, beta, investments, decision-making, Knightian uncertainty, robustness, information-gap, Galton's Error, real option value

JEL Classification: C20, G11, G12, G31

Acknowledgement 1 This paper was written when Cornelis Los was a Visiting Professor in Financial Management of the Peter Drucker School at Claremont Graduate University, where Satjaporn Tungsong was earning her M.Sc. in Financial Engineering. Drucker MBA Edward Tsai drew the charts. The paper has benefitted from many comments and suggestions by faculty and students in Finance Seminars at the Universities of Lethbridge and Calgary, with particular thanks to Professors Eldon Gardner, Robert Elliott and Gordon Sick. This paper has been presented at the 43rd Euro Working Group for Financial Modeling meeting at the Cass Business School in London, UK, 4 - 6 September 2008 to an entusiastic crowd. It benefitted recently from insightful comments made by Professors Robert Schwartz and Bruce Weber on processes of market liquidity generation in their TraderEx trading simulator in their Equity Trading Microstructure Seminar at Baruch College, October 13-14, 2008. It is now scheduled to be presented at the annual South West Finance Association meeting in Oklahoma City, February 25 - 28, 2009.
\end{abstract}


Cornelis A Los, $\mathrm{PhD}^{*}$, and Satjaporn Tungsong, M.Sc. ${ }^{* *}$ *corresponding author: cornelis.los@uleth.ca

University of Lethbridge

Faculty of Management

Department of Finance

Lethbridge, Alberta T1K 3M4, CANADA

** co-author: satjaporn.tungsong@cgu.edu

Thammasat University

Thammasat Business School

Bangkok, THAILAND

December 2, 2008 


\section{Introduction}

The current stream of uncertain events in the global financial markets compel us to resurrect the almost century-old debate between two economic giants John Maynard Keynes of Cambridge University, UK, who proposed the now widely accepted probability-measurable concept of risk (Keynes, 2008; original 1920) and Frank H. Knight of Chicago, University, USA, who proposed the now almost forgotten concept of epistemic uncertainty due to lack of knowledge (Knight, 2006; original 1921). Part of their original verbal debate can now be presented in modern, simple algebraic and graphical, investment portfolio management terms, so that one can easily see how Knight complemented Keynes. One can also observe how Knight's fundamental concerns have been corroborated by the current financial market events. ${ }^{1}$

The problem of comparison of their arguments has been that, until now, no economist ever dared to analyze both concepts within the same well-known frames of reference of returns and risk of Markowitz and Sharpe. Markowitz frame of reference, with mean return and volatility axes, shows that Knightian uncertainty can be precisely located and interpreted, while Sharpe's frame of reference of mean return axis and, unfortunately, downward biased beta axis, shows (1) what has been missing in his picture and (2) how large the Knightian uncertainty premium actually is (ca. 200 basis points).

I think that my simple algebraic and graphical interpretation and comparison facilitates the comparison between Keynesian risk (valuable by options) and Knightian epistemic uncertainty (due to lack of knowledge), which induces some scientific humility in the current crop of financial risk modelers. It also may help explain why institutions like the U.S. Securities Exchange Commission (SEC) experiences difficulties with biased investment model validations and with its definition of what constitutes "fair pricing." This paper is an elaboration and extension of my basic argument in Los (1999) that biased investment models imply "unfair pricing," since they

\footnotetext{
1 Another person recently warning for what is now happening is Taleb (2007), whose skeptic and almost cynical views can be contrasted with the more benign views of Bernstein (1996).
} 
under-represent the total amount of uncertainty ("financial risk") in the valuation data. The private sector exhibits this modeling uncertainty as "model envy" among quants (Das, 2006, pp. 208-209).

The current turmoil in the financial markets is mainly traceable to existing scientific hubris of financial risk modelers, who leveraged their firms too far to be reasonable (with balance sheet leverage ratios of 30-300 times), thinking that their Keynesian risk models could balance (hedge) their risks. Their strategists and executives too easily forgot about their own fundamental financial market ignorance $=$ information gap, in particular their ignorance of how financial systems empirically function, given their microstructural limitations.

Almost a decade ago, in response to an much earlier warning by Wassily Leontief in his letter to Science in 1982 discussed in Los (1991), I published an article about the modeling bias of "Galton's Error" of unilateral projection and the unfair consequence of modeling uncertainty for fair pricing (Los, 1999). Recently this topic has so dramatically gained in actuality that the Global Association of Risk Professionals (GARP) devoted a whole issue of its flagship publication to "The Uncertainty Dilemma," with an Editorial by its Chief Editor Robert Sales on "Seeking Answers in Volatile Times: The Burden of Uncertainty" (GARP Risk Review, 2008, p. 1). Sales states that "The ability of models to incorporate uncertainty into the valuation process, particularly in volatile markets, is one of the challenges addressed in this issue's cover story" (p. 12)." From his Editorial and the following articles it is clear that Sales referred to a broader concept of uncertainty than the Keynesian "probabilistic risk."

Page 31 of the Tuesday, September 16, 2008 issue of The Wall Street Journal stated, under the title "Keys to gauging economic fallout," in a directly credit risk premium related fashion:

"But the already wide gap - the "spread" in market lingo - between yields investors demand on risky securities and those demanded on safe U.S. Treasury securities widened significantly. Those spreads are a key reflection of confidence (or lack 
thereof) among investors and a measure of the extent to which financial conditions are constraining the conomy. The question now is how much wider thoise spreads get."

Indeed, how wide can such credit spreads become? What are the maximum credit risk spreads due to lack of knowledge? How volatile are these assessed risk premiums? My Galton's Error critique of conventional bivariate Capital Asset Pricing Model (CAPM)-based investment decision-making (Los, 1999), which is reviewed in this paper, shows that, when there is serious information gap, ${ }^{2}$ most investment decision-makers prefer to ignore this lack of information, providing evidence of their ambiguity aversion (a term attributed to Fox and Tversky, 1995). In my subsequent book on financial market risk analysis and measurement (Los, 2003, Chapter 1), I redefined uncertainty as a much broader concept than the usual probabilistically measurable risk: "uncertainty $=$ (measurable, and thus insurable) risk + ignorance (= lack of information)." Measurable or Keynesian probabilistic risk information is well covered by modern option theory. But Knightian uncertainty due to incomplete, or lack of, information is hardly, if ever, discussed in the financial literature, at least not since the 1920s. ${ }^{3}$ In particular, empirical option pricing is seriously affected by our deficiency of knowledge about, for example, the levels of persistence of financial markets (e.g., about the time distribution of trading events), a financial valuation issue that only few have researched in detail (Cf. Jamdee and Los, 2007, for an overview).

Moreover, I found that the issues of uncertainty due to lack of knowledge are related to the Ellsberg Paradox, a well-known paradox in decision theory and experimental economics. This Paradox demonstrates that people's decision-making may violate the tenets of expected utility theory, thereby providing more evidence for ambiguity aversion, which cannot be accounted for

\footnotetext{
${ }^{2}$ In my Los (1999) article, I called it the "ignorance gap," but that is, strictly speaking, incorrect since we are dealing with a gap in our information or knowledge, not a gap in our ignorance. However, the measurement of our information gap is a, skeptical but plausible, measurement of our ignorance.

3 There can be no doubt that Frank Knight viewed his concept of uncertainty as unhedgeable, since he clarified his view in the "Preface for the Reprint of 1957" of his book Risk, Uncertainty and Profit (page lxii): "The word "uncertainty" semed best for distinguishing the defects of managerial knowledge from the ordinary "risks" of business activity, which can feasibly be reduced if not eliminated by applying the insurance principle through some organization for grouping cases." (Knight, 2006)
} 
by utility theory (Los, 2003, pp. 16-17). $\quad$ Remarkably, this Paradox holds true regardless of any utility function or risk aversion. Thus, ambiguity aversion is, indeed, a concept different from the more familiar financial concepts of risk aversion or Tobin's liquidity preference.

In reaction to the Asian Financial Crisis of 1997, my 1999 critique of the use of Galton's Error of bivariate unilateral projection technology to compute betas was followed by similar critique of the use of multivariate unilateral projection technology in the context of complex multi-assetmulti-country-multi-currency portfolio management (Los, 2006).

Recently I learned that mathematicians Ben-Haim and Sniedovich are currently probing similar non-probabilistic decision-making theory issues in a more general fashion (Ben-Haim, 2006; Sniedovich, 2007). Ben-Haim's information (info-) gap decision theory is a non-probabilistic decision theory seeking to optimize robustness to failure, or opportunities for profit, under severe uncertainty. This so-called Knightian (severe or strict) uncertainty theory is very different from the theories of decision-making under Keynesian probabilistically measurable risk, discussed by Dixit and Pindyck (1994). The modeling of Knightian uncertainty is done as an information-gap based on incomplete, or lack of, information rather than as a known or measurable probability distribution (Ben-Haim, 2006, p. xii). An information-gap model does quantify the possible range of uncertainty and its premium consequences, but without any measure function.

Sniedovich (2007) is critical of Ben-Haim's information-gap models, which, he asserts, generically resemble Wald's Maximin models (Wald, 1945, 1950) and, therefore, can lead to only locally optimal and, therefore, rationally limited decisions. However, this paper demonstrates that this is a very doubtful, if not outrightly wrong, assertion, since information gap decision models do not use any probabilistic measure function: they focus on the incompleteness or lack of information inherent in the uncertain data.

\footnotetext{
4 This Paradox was popularized by Ellsberg (1961), although a version of it was already noted by Keynes (Keynes, 1921, pp. 75-76, p. 315, ft. 2). However, Keynes confused the issue by introducing the concept of "subjective probability." It was actually Keynes' Chicago School opponent Knight (2006; original 1921) who made the scientifically essential distinction between measurable, probabilistic and thus insurable risk, and nonprobabilistic uncertainty due to lack of information, which is non-insurable.
} 
Wald's Maximin model underlies Markowitz portfolio optimization, by maximizing the average returns and minimizing the risks of portfolio investments (Markowitz, 1952). But Wald's Maximin model does not take account of incomplete information about all possible "states of Nature," and of ambiguity aversion and its consequent thirst for scientific R\&D, which can expand the known set of "states of Nature" and reduce Sniedovich's "region of severe uncertainty." Wald's Maximin decision function, and thus also Markowitz portfolio optimization, relies on an existing known set of states of Nature and does not incorporate possible expansion of the knowledge by additional R\&D. ${ }^{5}$

Although the rationality of investment decision-making under uncertainty is, indeed, limited, it is only limited by lack of information, including lack of information which states of Nature are measurable, even if that is only in a relative frequency fashion.. Such a limit can always be rationally pushed further out into the average return/uncertainty space by seeking more investment information, e.g., by R\&D. Knightian information-gap models have already been studied or applied in a wide range of applications, including engineering, biological conservation, theoretical biology, homeland security, economics, project management, meteorology, earthquake analysis, and statistics, but only recently in financial-economics (Ben-Haim, 2004).

In economics, Shackle's 1972 "non-distributional uncertainty variable" bears some similarity to an information-gap variable (Shackle, 1992, p. 23), but there has been no follow-up in the financialeconomic literature until recently. In reaction to the severely uncertain Asian Financial Crisis of 1997, we already predicted (Los, 1999; and 2003, pp. xxi-xxxi) that the broader uncertainty analysis would find a natural home in financial-economics in the context of both the increased occurrence of irregular financial "crises" (as Ben-Haim, 2005, and, in particular, Beresford-Smith and Thompson, 2007, demonstrate, and as Taleb, 2006, discusses) and in the context of the recent concerns of the Security and Exchange Commission (SEC) about what constitutes "fair pricing"

\footnotetext{
${ }^{5}$ Sniedovich error of assertion is similar to that of the adherents to the Intelligent Design of the Universe, who presume to know all "states of Nature," like all the black and red numbers on a wheel of fortune. Human knowledge is inherently limited, expandable and replaceable, i.e., incomplete.
} 
(Cf. Hughes, Guerrera and Chung, 2008, regarding the SEC's concern regarding SFAS 157 on "fair value measurement").

Non-probabilistic Knightian model uncertainty has serious consequences for the fair pricing of companies and investments in general. But these issues were thought to be indiscussible in the conventional financial-economic theoretical context. I've received many personal, and sometimes vehemently negative reactions, to my 1999 critique of Galton's erroneous use of unilateral projections to represent the information content of uncertain data. Perhaps, there was a good reason for the remarkable silence in the financial literature about such a fundamental financial valuation oversight. Most of my academic and professional respondents acknowledged that my critique was correct, but they also confided that they could not imagine how to incorporate the consequences of Knightian uncertainty or lack of information in the standard textbook explanations of capital asset pricing (CAPM) and arbitrage pricing theory (APT) of Corporate Finance, Portfolio Management, and Investments or what consequences it could have for investment valuations. Following Keynes (1921) suggestion, they substituted subjective probabilities for incomplete or lack of information, often in a Bayesian fashion.

This paper attempts to fill all those lacunae by demonstrating algebraically, graphically, and empirically, both in bivariate Markowitz mean-variance (CML) and Sharpe mean-beta (SML) frames of reference, how such Knightian uncertainty or information gap can be represented using the original rates of return covariance information. It demonstrates how the value consequences of Galton's Error can be made visible in finance textbook examples and what impact such modeling uncertainty has on fair pricing. As an unexpected, but felicitous result, this paper is also able to explain why traders and investors receive not only "buy" and "sell" signals based on the comparison of market prices and intrinsic values, but also "hold" signals, and why, therefore, they often remain undecided about investment and trading decisions.

Investors and traders are often ignorant of the extent of the uncertainty of their decisionmaking, since the computed risk premia, which are supposed to compensate for risk taken, are 
themselves not robust. The consequential behavior of traders (in particular, the decision to "hold" because of ignorance of the extent of the uncertainty) is directly related to people's observed ambiguity aversion: people prefer a sure thing over a gamble. Indeed, another famous financialeconomic Paradox presaged such inconsistency of actual observed financial choices with the predictions of expected utility theory. Allais (1953) argues that it is not possible to evaluate portions of decision choices independent of other choices presented. The Allais Paradox is the counterexample for the presumed independence of the decision alternatives and the existence of complementarity. Investment decision-makers prefer a sure thing over a gamble. Only when there is a sure trading decision, there will be buying or selling action. In the case of Knightian uncertainty (due to lack of knowledge), investors prefer to hold on to their existing investments, even when they rapidly decline in value.

It is important to emphasize that this paper builds on the venerable CAPM, which is a theory about the ways assets are priced in relation to their risk. This theory was simultaneously and independently, discovered by Lintner (1965), Mossin (1966) and Sharpe (1964, 1970, who received a Nobel Prize for it), and is now part-and-parcel of any standard textbook on investments (Cf. Bodie and Marcus, 1999). We extend Haugen's (2001, in particular, Chapters 8-9) as one of CAPM's mathematically most precise textbook explications, so that it can incorporate and represent the Knightian uncertainty. ${ }^{6}$

This paper is organized as follows. First, I review very concisely my original demonstration of Galton's Error of unilateral projections to model systematic information in the data, its consequent modeling bias and the existence of a measurable information gap. Then I update my original 1995 empirical example of how it affects the (still) deficient risk categorization of fund investing in 2007.

\footnotetext{
${ }^{6}$ For the simplicity of textbook-like exposition, this paper accepts all three conventional Assumptions made in that text (Haugen, 2001, pp. 202-205):

"Assumption I: Investors can choose between portfolios on the basis of expected return and variance" (p. 201);

"Assumption II: All investors are in agreement regarding the planning horizon and the distribution of security returns" (p. 205); and

"Assumption III: there are no frictions in the capital market" (p. 205).

Of course, these three Assumptions can be relaxed and made more realistic in the real world, as they are and have been in many empirical cases.
} 
Next, the concept of idiosyncratic risk is analyzed and, in another empirical example, industry sectors are ranked according to their recent levels of such idiosyncratic risk. Third, adjusting one of Haugen's examples in the context of Markowitz' portfolio selection, idiosyncratic risk is measured relative to the Capital Market Line using Sharpe Ratio analysis, given a simple measurement of the extent of our information gap. Fourth, Knightian uncertainty is then analyzed in the context of CAPM's Security Market Line analysis. Again the extent of the uncertainty range of the idiosyncratic risk premium is measured and I demonstrate why there must be considerable "hold" signals in addition of the usual "buy" and "sell" signals. This uncertainty range provides the liquidity space that makes market-making possible.

The less market correlated an asset is, the more idiosyncratic risk an asset contains. The maximum idiosyncratic risk is provided by a risky asset with the same average return as risk-free cash, which is the most liquid asset. Both, this most speculative asset and cash, have a market correlation of zero. The fifth section is taking Galton's Error of unilateral projection and the proven existence of Knightian uncertainty still one step further into fundamental present value analysis of growth opportunities in the context of real options valuation. The paper concludes with some generalizations and comments on the investment, trading, and regulatory policy consequences of this epistemological - Knightian non-probabilistic uncertainty - extension of Dixit and Pindyck's (1994) "decision-making under (probabilistic) uncertainty."

\section{Galton's Error and Knightian Uncertainty}

In this paper the implications of Knightian, epistemological, or model uncertainty for investment valuations are traced in the contexts of portfolio selection, capital asset pricing and real option pricing. In this Section 2, I very concisely review and summarize the essence of my earlier ( Los, 1999) argument of Galton's Error to use only one projection to represent and model the signaling information in the data at the expense of some esential risk information. Such an omision of essential risk infomation in the computation of the beta leads to a downward bias 
in the beta and leads to the omission of the essential category of "undecided" in the complete beta-classification (aggressive, neutral, defensive, and - the often omitted category of undecided). Figure 1 (reproduced from Los, 1999, p. 1809) provides a very brief analytic summary of that earlier paper and functions as a beacon or point of reference for the following discussion. The main point is that for empirical data the coefficient of determination is less than $100 \%$ and that there exists "lack of information" gap, which has not been incorporated in the financial literature with major model bias consequences for investment valuation and model validation. The following sections attempt to remedy that deficiency in model validation.

\section{[PLACE FIGURE 1 ABOUT HERE]}

First, the implications of the existence of model uncertainty for the empirical computation of correlations and beta or relative risk coefficients can be traced to the usually published projections and their often forgotten equivalent inverse projections. The covariance data of two variates, e.g., the rate of return of a firm, fund, security, or project investment $i$ and the rate of return of a market index $M$ is always summarized in the symmetric $2 \times 2$ data covariance matrix

$$
\Sigma=\left[\begin{array}{cc}
\sigma_{i i} & \sigma_{i M} \\
\sigma_{i M} & \sigma_{M M}
\end{array}\right]
$$

where $\sigma_{i M}$ is the covariance between the two respective rates of return, while $\sigma_{i i}$ and $\sigma_{M M}$ (= $\sigma_{i}^{2}$ and $\sigma_{M}^{2}$ in the conventional statistics notation. I prefer to use the double indices to indicate the variance or covariance, respectively) are the respective variances. Using the covariance information of this matrix, bivariate empirical model uncertainty of the (linear) relationship between the two rates of return can be concisely expressed in five equivalent ways (but usually aren't):

(i) $|\Sigma|=\sigma_{i i} \sigma_{M M}-\sigma_{i M}^{2}=\sigma_{i i} \sigma_{M M}\left(1-\sigma_{i M}^{2} / \sigma_{i i} \sigma_{M M}\right)=\sigma_{i i} \sigma_{M M}\left(1-\rho_{i M}^{2}\right) \neq 0$, the determinant of the data covariance matrix $\Sigma$ is unequal zero. This implies that

(ii) $0<\rho_{i M}^{2}=\sigma_{i M}^{2} / \sigma_{i i} \sigma_{M M}=\left(\sigma_{i M} / \sigma_{M M}\right) /\left(\sigma_{i i} / \sigma_{i M}\right)=\beta_{L} / \beta_{U}<1$, the coefficient of determination is less than $100 \%$ and shows inexact determination, i.e., there is incomplete model explanation. Moreover, as is clearly visible in Fig. 1, 
(iii) the usual "vertical" orthogonal projection is $\beta_{L}=\sigma_{i M} / \sigma_{M M}=\tan \left(\theta_{1}\right)<\tan \left(\theta_{1}+\theta_{2}\right)=$ $1 / \tan \left(\theta_{3}\right)=1 /\left(\sigma_{i M} / \sigma_{i i}\right)=\beta_{U}$, i.e. smaller than the "horizontal" (or inverse) projection and thus the computed slopes of these two orthogonal projections don't coincide. It is important to emphasize that the inverse projection is as valuable and, because of the symmetry of the covariance matrix, cocepually equivalent to the "usual" projection. Omitting this projection omits essential data variance information of the rates of return i from the beta computation. Willfully omitting essential information is bad science and bad investment practice In Fig. 1 it is clearly visible that

(iv) $0<\theta_{2}<\frac{\pi}{2}$, there exists a clearly defined Knightian information gap; and

(v) $\frac{N}{S}=\frac{\sin \theta_{2}}{\sin \theta_{1} \sin \theta_{3}}=\frac{\left(1-\rho_{i M}^{2}\right)}{\rho_{i M}^{2}}>0$, there is a positive noise/signal ratio, i.e., there exists noise, since the inexact data contain some noise in addition to the signal. Thus the data confirm that the resulting computed linear model and beta slope is uncertain.

To amplify this last point: if there is some noise in the empirical data (and there usually is!), i.e., the data are not exact and we are confronted with our information gap of Knightian uncertainty, $\left(1-\rho_{i M}^{2}\right)$, expressed as a percentage of the total data variation $\sigma_{i i} \sigma_{M M}$. If the data were exact $\left(1-\rho_{i M}^{2}\right)=0$, or $\rho_{i M}^{2}=1$. Thus, the uncertainty gap percentage $\left(1-\rho_{i M}^{2}\right)$ measures the extent of our lack of information without the use of a probabilistic measure function. It is Galton's Error to only accept (and publish!) $\beta_{L}$ as "the (only) estimate" of the slope coefficient $\beta$, since it omits the $\sigma_{i i}$ variance (volatility) information about the investment return $i$ and only uses the market variance $\sigma_{M M}$ and the market covariance $\sigma_{i M}$. For a complete picture of the available model information on should never omit such essential data information. It should now be obvious that with uncertain empirical data there is a (limited) range of possible estimates $\left[\beta_{L}, \beta_{U}\right]$, which represents the empirical model uncertainty.

\subsection{Systematic Risk Categorization of Mutual Funds in 1995 and 2007}

Los (1999) demonstrates the consequences of Galton's Error and the information gap for the systematic risk and beta-categorization of 3,125 (out of an original 7,051) mutual funds in Morn- 
ingstar's Principia for Mutual Funds Universe in 1995. This analysis is updated for 2007 in Table 1 for 16,354 funds (out of an original 20,340) funds from the equivalent Morningstar Principia MUTUAL FUNDS ADVANCED data base as of November 30, 2007.

\section{[PLACE TABLE 1 ABOUT HERE]}

The number of appropriately selected funds (= those with a computed $\beta_{L}$ and $\rho_{i M}^{2}$ ) was in 2007 five times larger than in 1995. While the percentages of truly defensive and neutral funds remained about unchanged ( $21.4 \%$ in 2007 versus $18.4 \%$ in 1995, respectively, $1.1 \%$ in 2007 versus $0.6 \%$ in 1995), the percentage of undecided funds was cut almost in half (from $46.3 \%$ in 1995 to $21.7 \%$ in 2007) in favor of the category aggressive funds (from $34.2 \%$ in 1995 to $55.8 \%$ in 2007). Thus, the percentage of the defensive funds remained almost unchanged in more than a decade, while the percentages of both the aggressive funds and the undecided funds in 2007 was more than double in 1995. This signifies a shift to the construction and marketing of more aggressive and risky funds to satisfy the growing (global) demand for better average returns, of course, at the expense of more speculative risk-taking.

Our initial motivation in Los (1999) was to expose the marketing folly of categorizing funds as defensive (63.7\% under the then prevailing AIMR Performance Presentation Standards, while in effect more than half of them (46.3\% of the total in 1995) should be properly classified as undecided. Under the same misleading, but industry-recommended performance standards, the current CFA-Institute beta-classification would make us still believe that $43.1 \%$ of the funds are defensive, while in fact only half of that percentage (21.4\%) truly is, while the other half $(21.7 \%)$ should be categorized as undecided. The category "undecided" does figure neither in the CFA's beta-categorization nor in the standard financial textbook beta-categorizations, a clear indication of ambiguity aversion by financial economists. Any ambiguity in such investment decision-making is effectively averted by ignoring it, of course, at the great peril of actual investors. But it is not necessary to ignore such ambiguity. In fact, it is easy to account for model uncertainty and ambiguity, even in the simplest finance textbook examples, as the following examples will 
demonstrate.

\section{The Certain Capital Market Line (CML) and the Uncer- tain Security Market Line (SML)}

Similar to the standard financial textbooks, for the simplicity of explanation, this paper follows Markowitz $(1952,1987,1991)$ by making two assumptions. First, we assume that the distribution of portfolio returns can be described by only two relevant parameters, the mean and the variance. In order to be able to choose portfolios based on expected return and variance only, we also assume a quadratic relationship between our utility and the value of our portfolio (Tobin, 1958).

We assume that a risk-free rate exists, e.g., a U.S. Treasury bill or zero-coupon bond maturing at the end of the planning (or investment) horizon and with its payment guaranteed by the government. In the following numerical examples, that risk-free rate is taken to be $3.5 \%$ (as of January 22, 2008, after the Fed cut the Fed funds rate by 75 basis points). Because of the existence and general availability of this risk-free rate, it makes sense that all market participants hold the same portfolio of risky investments, indicated by portfolio $M$ in Figure 2. This portfolio is the portfolio in the efficient set with the highest Sharpe Ratio (Sharpe, 1970):

$$
\left[E\left(r_{M}\right)-r_{F}\right] / \sigma_{M}
$$

Figure 2 is our extension and Knightian uncertainty adaptation of Figure 8.8 in Haugen (2001, p. 210) and it is the central theoretical Figure of this paper.

[PLACE FIGURE 2 ABOUT HERE]

Since in this simple version of CAPM everyone is holding the same portfolio $M$ of risky investments, the contribution an investment $i$ makes to the market portfolio can be measured by the covariance between its returns and the returns of the market portfolio, which can be more revealingly expressed by using the correlation coefficient, as follows:

$$
\rho_{i M}=\left[\beta_{L} / \beta_{U}\right]^{0.5}
$$


, i.e., as the ratio between the lower and upper beta, so that the covariance:

$$
\begin{aligned}
\sigma_{i M} & =\sigma_{i} \sigma_{M} \rho_{i M} \\
& =\sigma_{i} \sigma_{M}\left[\beta_{L} / \beta_{U}\right]^{0.5}
\end{aligned}
$$

In other words, three risk factors play an equal role in the contribution of investment $i$ to the market's valuation: the volatility of investment $i$ 's returns, $\sigma_{i}$, the volatility of the market's returns, $\sigma_{M}$, and the Knightian model uncertainty, here expressed by the beta ratio $\beta_{L} / \beta_{U}$. The conventional finance textbook presentation mentions only the first two factors and ignores the beta information gap, i.e., it ignores the existence of Knightian uncertainty.

\subsection{Certain Capital Market Line}

This Knightian uncertainty will first be graphically presented in Figure 3, which is our extension and adaptation of Figure 8.12 in Haugen (2001, p. 216), and then discussed in detail using Sharpe's Ratio analysis. Figure 3 looks in detail at the Markowitz portfolio space in which Sharpe Ratio analysis takes place. Sharpe Ratio analysis implies the allocation of investment $i$ 's total risk over its hedgeable systematic risk and non-hedgeable idiosyncratic risk. It is only idiosyncratic risk which provides investment $i$ with its comparative advantage in a competitive market analysis, since only taking idiosyncratic risk generates truly profitable investments.

\section{[PLACE FIGURE 3 ABOUT HERE]}

\subsection{Sharpe Ratio Analysis}

The Sharpe Ratio of firm $i$ or its risk premium per unit of risk, also known as the price of its risk (measured by the standard deviation of its total rates of return), is a percentage of the price of the market's risk, and can be measured in various ways: by the lower projection of the firm's beta 
or by its upper projection and its coefficient of market determination, as follows:

$$
\begin{aligned}
{\left[E\left(r_{i}\right)-r_{F}\right] / \sigma_{i} } & =\beta_{L}\left[E\left(r_{M}\right)-r_{F}\right] / \sigma_{i} \\
& =\rho_{i M}^{2} \beta_{U}\left[E\left(r_{M}\right)-r_{F}\right] / \sigma_{i} \\
& =\left[\sigma_{i M} / \sigma_{M M}\right]\left[E\left(r_{M}\right)-r_{F}\right] / \sigma_{i} \\
& =\left[\sigma_{i M} / \sigma_{i} \sigma_{M}\right]\left[E\left(r_{M}\right)-r_{F}\right] / \sigma_{M} \\
& =\rho_{i M}\left[E\left(r_{M}\right)-r_{F}\right] / \sigma_{M}
\end{aligned}
$$

Thus, the Sharpe Ratio of firm $i$ is a correlation coefficient $\rho_{i M}-$ multiple of the Sharpe Ratio of the market $M$, which measured the slope of the Capital Market Line in Markowitz' mean-risk $\{E(r), \sigma)\}-$ space.

\section{Box 1: Market Efficiency and the Dispersion of Sharpe Ratios}

In the Spring of 2008, immediately after the substantial stock market correction of January 16, 2008, I did a little experiment with my MGT402 Asset Management Practicum class of the Peter F. Drucker and Masatoshi Ito School at the Claremont Graduate University. The class consisted of 44 candidates for the M.Sc. in Financial Engineering degree, 11 candidates for the MBA Finance degree, one candidate for the MA degree in Economics, and three Senior Honor students in the $4+1$ program. These 59 students came from the China (34\%), India (31\%), USA (25\%) and other countries (9\%) and had widely differentiated educational backgrounds and professional experiences. At the beginning of the 2008 spring semester each of these students received a brokerage account with a fictitious $\$ 500,000$ (in Treasury bills) and 200 trades on STOCK-TRAK Global Portfolio Simulations (www.stocktrak.com) and was encouraged to build a portfolio. Round-the-clock trading started on January 28, 2008 and ended on April 30, 2008. All students started their trading with a Sharp Ratio - the risk-adjusted measure using standard deviation and excess portfolio return calculated 
to determine reward per unit of risk - equal to zero. The risk-free rate for these Sharpe Ratio calculations was $3 \%$ annual compounded daily. They could trade stocks, bonds, mutual funds, commodities, options, futures, and future options. They could buy, sell, buy on margin, and sell short most stocks, options and funds traded in both the United States and Canada and use limit and stop orders. They could also buy and sell stocks from the world's exchanges, including London, Hong Kong, etc. Weekly their portfolio and Sharpe Ratio rankings were shown to encourage intra-class competition. After three months of trading, the evenly distributed Sharpe Ratios of the students' individual portfolios ranged from a minimum of -3.51 (negative risk premium) to a maximum of +3.38 (positive risk premium), with 33 students having positive Sharpe Ratios and the remaining 26 having negative Sharpe Ratios. The Sharpe Ratio of riskfree interest investment only was 0.39. One Indian student, Deep Thomas Moolayil, turned out to be a sensitive expert commodity trader, who took advantage of the strong markets in wheat, soy beans, oil, gold, platinum and palladium: within three months he ended up with $\$ 4.9$ million and would be a real asset to a commodity trading firm like Cargill, Inc. in Minnetonka, MN. His Sharpe Ratio was 2.21. I placed a few trades myself and ended up with $\$ 686,121$ with a Sharpe Ratio of 1.88 . The message of this exercise was that global portfolio investing is currently a very efficient business with winners and losers almost equally distributed over time, once all financial and model uncertainties are taken into account. This is quickly generated empirical evidence for the theoretical truth of Figure 3.

\section{Idiosyncratic (Firm-Specific) Risk}

The total market risk is measured by the variance of the total returns of an accepted benchmark market index, e.g., the S\&P500 Index $\sigma_{M M}\left(=\sigma_{M}^{2}\right.$ in the conventional statistics notation). Furthermore, we maintain that the probabilistic total risk of investment (firm, or security) $i$ is 
measured by the variance of its total returns $\sigma_{i i}\left(=\sigma_{i}^{2}\right.$ in the conventional statistics notation). In the Markowitz space we often portray the standard deviation or volatility $\sigma_{i}=\sigma_{i i}^{0.5}$, i.e. the square root of this variance. We have already encountered the coefficient of market determination of investment $i, \rho_{i M}^{2}$, so that we can present the allocation of the total investment risk over systematic (market) risk of firm $i$, as percentage of its total risk in terms of the information gap

$$
\sigma_{i i} \rho_{i M}^{2}=\sigma_{i i}\left[\beta_{L} / \beta_{U}\right]
$$

Or, we can present, in a completely equivalent way the idiosyncratic (firm-specific) risk of firm $i$, as percentage of its total risk

$$
\sigma_{i i}\left[1-\rho_{i M}^{2}\right]=\sigma_{i i}\left[1-\beta_{L} / \beta_{U}\right]
$$

On May 18, 2008, Professor Robert Merton pointed out in his Honorary Doctorate lecture at the School of Mathematical Sciences of Claremont Graduate University, that individual investments (projects, firms, securities, industrial sectors, or, in his example, countries) distinguish themselves competitively by their idiosyncratic risk. In other words, their idiosyncractic risk, which is inherent in their technological and marketing innovations, determines their (David) Ricardian comparative advantage, which ensures that the (Adam) Smithian investment specialization and consequential trade amongst them, leads to rising living standards and increases in wealth. He also showed that simple derivative financial instruments, such as swaps (itself a trade of different cash flows and thus of different risks) can help to swap the idiosyncratic risk for systematic and thus insurable risk.

In other words, a swap can reduce the information gap $\left[1-\rho_{i M}^{2}\right]$, of course, for a price. Thus a swap arrangement intermediates the risk level between diversifiable, but unique idiosyncratic risk and non-diversifiable, non-unique systematic risk. A swap can therefore reduce or enhance idiosyncratic risk of a particular firm and make it less competitive (more behaving like the market portfolio) or more competitive (more behaving idiosyncratically). When a swap reduces idiosyncratic risk, it increases an investment's Sharpe Ratio, so that an investment aligns itself more with 
the CML. When a swap increases idiosyncratic risk, it reduces an investment's Sharpe Ratio, so that an investment distinguishes itself and behaves less like a CML investment. Therefore a swap does not reduce the total risk of a particular investment. It only changes the allocation between insurable market risk and non-insurable idiosyncratic risk, and in return it transfers some value from the risk-aversive insurer to the risk-taking speculator. Going a little bit ahead of the main story of this paper, a swap does not alter the total investment risk $\sigma_{i}$, but can enhance the average return of a particular investment, by reducing the information gap and moving the investor closer to a higher rate of average return $E\left(r_{i}\right)$, by transferring the investor to a higher correlation $\rho_{i M}$-ray in Fig. 3.

A well-known but interesting observation with respect to Figure 3 is that the highest average rate of return for a given market can be obtained by being $100 \%$ invested in the market index, short of borrowing. But that with borrowing, i.e., by leveraging up, one can move along the CML (In the NE direction in Fig. 3). That is, the highest rates of return are only obtained by being $100 \%$ correlated with the market, i.e., when $\rho_{i M}^{2}=\beta_{L} / \beta_{U}=1$ and there is no Knightian modeling uncertainty. Of course, the market index itself can have a very high ex-post measurable risk $\sigma_{M}$, as we experienced, for example, in 2008, against which one can only preventively hedge by moving into cash (In the SW direction along the CML in Fig. 3).

Another, less-known, interesting observation is that the investment or asset with the maximum amount of idiosyncratic risk, i.e., when all its measurable risk is idiosyncratic and the investment is most speculative, it is, indeed, completely uncorrelated with the market. That investment has the same average return as risk-free cash, the most liquid of assets, which is completely uncorrelated with the market and the least speculative. Thus, the most speculative investments have the same average return as the least speculative investment (= cash) and both are completely uncorrelated with the market. Risk-free cash is thus a natural terminal asset for the risk-continuum of risky assets with the same average return as cash. Moreover, for a speculative investment to gain a higher average return than the risk-free rate, it needs to have some positive correlation with the 
market. For a speculative investment to have a lower average return than the risk-free rate, it needs to have some negative correlation with the market.

Figure 4 provides an empirical industry sector counterpart of our theoretical Figure 3. For example, the utilities industry has a total risk of about $\sigma_{u}=21.9 \%$. This is allocated over $5.5 \%$ market risk and $16.5 \%$ idiosyncratic risk, with a market correlation of only $\rho_{M, u}=0.0039=0.39 \%$. In contrast, the financial services industry has a total risk of about $\sigma_{f s}=25.9 \%$, allocated over about $10 \%$ market risk and $15.9 \%$ idiosyncratic risk. This shows an almost ten times higher market correlation of $\rho_{M, f s}=0.387=38.7 \%$.

\section{[PLACE FIGURE 4 ABOUT HERE]}

Thus the financial services industry has a higher total risk than utilities, it has market risk about twice as high as that of utilities, while its idiosyncratic level of risk is about the same as that of utilities.

\subsection{Ranking of Industry Sectors According to Their Idiosyncratic Risk}

It is clear from Table 2 that investments, in particular here industry sectors, show very large percentages of idiosyncratic risk, which determines their specific comparative advantage in their markets. Any decisions regarding investments into individual firms or into industrial sectors or

countries are subject to severe uncertainty. We will now trace the difficulties created by such large percentages of idiosyncratic risk for valuation modeling and how we can still arrive at some fairly robust investment decisions, even without the use of derivatives.

\section{[PLACE TABLE 2 ABOUT HERE]}

In Table 2 we notice that the following four industry sectors experience the highest levels of idiosyncratic risk, or technological specialization, and thus with the highest level of Ricaridan comparative advantage: utilities, health care, telecommunications and software. Utilities include very specialized electricity-generating installations, e.g. coal, gas, geothermic, hydro-, nuclear or solar electricity generating plants that are stationary and cannot be moved and are therefore au- 
tomatically specialized. Health care facilities or emergency rooms, hospitals, retirement homes have the same comparative handicap. Telecommunications installations are sometimes stationary, like cell-phone systems or geostationary satellite systems, and need very expensive hardware infrastructure. Software appears to be easily transferable, but in reality is very platform-specific or is protected by a strong patent, requiring high licensing fees, like Windows-based (not hard-wired) or Mac-based software (hard-wired).

\section{Uncertain Security Market Line and Idiosyncratic Risk}

The purpose of the Capital Asset Pricing Model (CAPM) is to compute a discount or "hurdle" rate $E\left(r_{i}\right)$, which depends on the level of market determination, or its counterpart, investment specific idiosyncrasy. It does so by computing an idiosyncratic risk-premium, derived from the market's risk premium, and then adding that idiosyncratic risk premium to the risk-free rate $r_{F}$. The conventionally identified Security Market Line (SML), by which these computations are accomplished, is described by the following well-known equation, which relates the investmentspecific risk premium to the market risk premium via a particularly measured relative risk ratio

$$
\left[E\left(r_{i}\right)-r_{F}\right]=\beta_{L}\left[E\left(r_{M}\right)-r_{F}\right]
$$

which we designate by $\operatorname{SML}(1)$ in Figure 5.

\section{[PLACE FIGURE 5 ABOUT HERE]}

This $\operatorname{SML}(1)$ has $E\left(r_{i}\right)$ on the vertical axis and $\beta_{L}$ on the horizontal axis. This investment $i$ 's risk premium is a $\beta_{L}-$ multiple of the market's risk premium. But this is not the only possible representation. When we substitute for $\beta_{L}=\rho_{i M}^{2} \beta_{U}$, we obtain a new Security Market Line, relating the investment-specific risk premium to the market risk premium via a differently measured relative risk ratio

$$
\left[E\left(r_{i}\right)-r_{F}\right]=\rho_{i M}^{2} \beta_{U}\left[E\left(r_{M}\right)-r_{F}\right]
$$

which we designate by $\operatorname{SML}(2)$ in Figure 5. This $\operatorname{SML}(2)$ has $E\left(r_{i}\right)$ on the vertical axis and 
$\beta_{U}$ on the horizontal axis. In other words, we need to have now two parallel $\beta$-axes, one to measure $\beta_{L}$ and one to measure $\beta_{U}$. Thus the relative risk $\beta$ is the parameter whose true value is subject to severe non-probabilistic uncertainty, which lies in a range of uncertainty $\left[\beta_{L}, \beta_{U}\right]$, where $\rho_{i M}^{2}=\frac{\beta_{L}}{\beta_{U}}$ measured by two projection estimates $\beta_{L}$ and $\beta_{U}$, respectively. ${ }^{7}$

Interestingly, this CAPM model satisfies the working assumptions of information-gap theory of Ben-Haim (2006). The range of uncertainty is potentially unbounded when the coefficient of determination $\rho_{i M}^{2}$ approaches zero, since $\beta_{U}=\frac{\beta_{L}}{\rho_{i M}^{2}}$ and both estimates are potentially very poor estimates of the relative risk $\beta$ and to be substantially wrong (Ben-Haim, 2006, p. 280281). In other words, the challenges faced by CAPM's valuation methodology are conceptually, methodologically and technically more considerable than even originally assessed in Los (1999). How should we proceed? We decided to proceed by determining the degree of robustness of the investment decisions that we can base on this valuation methodology, so that we can assess how could or bad its valuation measurement actually can be.

Both SML's have $\left[E\left(r_{M}\right)-r_{F}\right]$ as a common slope in Sharpe's mean-relative risk $\{E(r), \beta\}-$ space. This can easily be seen by looking at the market-neutral $\left\{E\left(r_{M}\right), 1\right\}$ point for $\beta_{L}$ designated by $E\left(r_{i}\right)=E\left(r_{M}\right)$ and $\beta_{L}=1$, and the market-neutral $\left\{E\left(r_{M}\right), 1\right\}$ point for $\beta_{U}$ designated by $E\left(r_{i}\right)=E\left(r_{M}\right)$ and $\beta_{U}=1$. At both points the slope of each $\operatorname{SML}(j ; j=1,2)$ is $\left[E\left(r_{M}\right)-r_{F}\right]$. However, in the first case of $\operatorname{SML}(1)$ for $\beta_{L}=1$, we have

$$
\left[E\left(r_{i}\right)-r_{F}\right]=\left[E\left(r_{M}\right)-r_{F}\right]
$$

but, in the second case of $\operatorname{SML}(2)$, for $\beta_{U}=1$, we have

$$
\left[E\left(r_{i}\right)-r_{F}\right]=\rho_{i M}^{2}\left[E\left(r_{M}\right)-r_{F}\right]
$$

\footnotetext{
${ }^{7}$ One of my financial engineering students asked me how this was possible: do these $\beta_{L}$ and $\beta_{U}$ both measure the relative risk $\beta$ ? Yes, they do, but their measurements are elastic and the robustness of their measurements depend on the degree of determination $\rho_{i M}^{2}$ provided by the original scatter plot of rates of return of the firm $i, r_{i}$, and the market rate of return, $r_{M}$. It is as if you have two elastic measurement tapes and both indicate the particular measurement to be 1 ("one"), but each measurement tape has a different actual length, because they are not rigid like a metal tape, but made of an elastic material. The length of such measurement tapes can even depend on the local temperature! The higher the temperature - the wider the scatter - the larger the range difference between the two measurements. Moreover, one cannot assert that one measurement, $\beta_{L}$, is a "better" (more "precise") measurement of the relative risk $\beta$ than the other, $\beta_{U}$. One can only assert that the difference between the two measurements (= information gap) is measured by the coefficient of determination $\rho_{i M}^{2}$.
} 
Therefore, the Knightian uncertainty of investment $i$ 's risk premium can be precisely measured by the difference between the relative positions of both SMLs, as follows

$$
\left(1-\rho_{i M}^{2}\right)\left[E\left(r_{M}\right)-r_{F}\right]
$$

i.e., by the lack of information percentage of the market's risk premium. This Knightian lack of information or ignorance percentage of firm $i$ 's risk premium is the direct counterpart of the Knightian information gap between the respective orthogonal beta projections, since $\rho_{i M}^{2}=\frac{\beta_{L}}{\beta_{U}}$. The non-probabilistic severity (or "width") of this information gap is measured by $\left(1-\rho_{i M}^{2}\right)$. This is a measure of the quality of the investment information and analysis available to investors and traders. By not including this Knightian information gap in the conventional textbook SML, Sharpe transferred (unwittingly, I'm sure!) Galton's Error of ignoring this information gap into the domains of Corporate Finance, Portfolio Management, and Investment valuation and decisionmaking. Galton's Error is likely to have resulted in countless misallocations of capital, since it leads to a severe underestimation of the rational (= taking account of all available information) hurdle rates.

Any investment that has an average return $E\left(r_{i}\right)$ below the $\operatorname{SML}(1)$ for a particular level of $\beta_{L}$-risk, has a too low average return for the given level of measured $\beta_{L}$-risk. The investments' market price is too high relative to its rational valuation and it should be sold. On the other hand, any investment that has an average return $E\left(r_{i}\right)$ above

$$
S M L(2)=S M L(1)+\left(1-\rho_{i M}^{2}\right)\left[E\left(r_{M}\right)-r_{F}\right]
$$

for a given level of $\beta_{U}$ risk, has a too high average return for a given level of measured $\beta_{U}$-risk. Its market price is too low relative to its rational valuation and it should be purchased. Between the two SMLs there is not enough information to make such clear-cut buy or sell decisions and the investors are advised to hold the investment if the investment is already purchased, or not to make the investment when no investment has yet been made. 
The maximal uncertainty of that investment decision process occurs when the coefficient of market determination $\rho_{i M}^{2}=0$, when the Knightian decision uncertainty is $100 \%$ and the rational investment decision uncertainty is maximally equal to the market risk premium $\left[E\left(r_{M}\right)-r_{F}\right]$. That occurs when the investment project exhibits only idiosyncratic risk and no systematic risk. Since the information gap $\left(1-\rho_{i M}^{2}\right)=100 \%\left(\beta_{L}=0\right.$ and $\left.\beta_{U}=\infty\right)$,

$$
S M L(2)=S M L(1)+\left[E\left(r_{M}\right)-r_{F}\right]
$$

may be called the ultimate robustness case, since $\operatorname{SML}(2)$ provides the highest hurdle rates with the greatest tolerable uncertainty for making rational investments, to purchase a firm or to start a project, and $\operatorname{SML}(1)$ provides the lowest hurdle rates to abandon investments and to sell a firm most profitably. In this fashion, we have now discovered a simple methodology to identify investment alternatives that are robust to the greatest information-gap uncertainty, which just extends the traditional version of the CAPM.

\section{Box 2: Rule of thumb for investing under extreme uncertainty: we can} now formulate a simple rule of thumb for investing with the greatest shortage of information, since most coefficients of market determination for individual investments, firms, industry sectors, etc. are close to zero (as we noticed in Table 3A: compute the hurdle rate for your investment opportunity using the conventional Sharpe Security Market Line SML(1) and add the current market risk premium (e.g., the 241 basis points market risk premium of our empirical example) to it to find the hurdle rate with the greatest tolerable risk premium for making an investment.

On the other hand, the minimal uncertainty of that decision process occurs when the coefficient of determination $\rho_{i M}^{2}=1$ and the Knightian information uncertainty equals zero, since then $\operatorname{SML}(2)=\operatorname{SML}(1)$. That zero Knightian uncertainty, or certain SML case may be called the $o p$ portuneness case since then only sweeping success is possible. But one must remain aware that the robustness of opportuneness case is nil. Interestingly, in that opportuneness case, investments are 
located on the Capital Market Line (CML). Such absolutely certain linear portfolio combinations have been advocated by Malkiel (1990) in his famous Random Walk Along Wall Street book since $1974 .^{8}$ It should be no surprise that Malkiel strongly recommended to be always on the CML, i.e., to invest along the linear combination of cash and the market index according to one's risk preferences, because on the CML the information gap equals zero: $\left(1-\rho_{i M}^{2}\right)=0$ and investment decisions are no longer ambiguous.

Thus, Malkiel's investment recommendations appeal to investors who are ambiguity-averse. Malkiel's ambiguity-aversion differs from Tobin's liquidity-preference, although they are related as follows. Tobin's liquidity-preference explains the existence of the CML (Tobin, 1958). But Malkiel's ambiguity-aversion recommends to move out of Markowitz' portfolio, encompassed by the parabolic opportunity frontier in Fig. 2, towards the CML. This can be done, as Merton suggested by swapping risks.

Since the robustness of that Malkiel's recommended CML-based investments is nil, even the smallest changes in investment information and thus of financial market circumstances must lead to instantaneous changes in such CML-based investments. The consequential rebalancing of the investment portfolios may cause an unforeseen accumulation of transaction costs (which are assumed to be zero in this paper for the sake of explication!). Thus Malkiel's extremely conservative, opportune, but non-robust recommendation to always position one's portfolio on the CML is expensive for actual investors, when transaction costs are taken into account. New investment information, e.g., publicly available technological innovations obtained by R\&D, may shift the CML in either the propitious or the pernicious direction. The propitious direction of CML would be the upward rotation in Fig. 3 and the pernicious direction would be the downward rotation. Thus, technological innovations can be a double-edged sword for the financial market. The rotational direction of the CML is determined by the dynamic movement of the location of the overall financial market index in the mean-risk space, $E\left(r_{M}, \sigma_{M}\right)$. The overall level of the CML is determined by the

\footnotetext{
${ }^{8}$ His book is still widely read, and correctly so, and is currently in its 8 th edition.
} 
cash return $r_{F}$, indirectly controlled in the USA by the Federal Reserve, and thus by the level of the Treasury term structure available to the investment market.

One must realize that, on an individual investment project, sector, or firm $i$ basis, the relevant Sharpe Ratio line of such a project, industry sector or firm $i$ can also be rotated in the propitious (upward) or pernicious (downward) direction by more investigative research by financial analysts. The dissemination of the results of their financial research may increase or decrease the market determination of a such a investment project, sector or firm $i$ and increase or decrease its correlation $\rho_{i M}$ with the overall market. In this fashion an investment's own Sharpe Ratio will become more or less aligned with the Sharpe Ratio of the CML.

Therefore, the dynamic CML-based investment decision model of Fig. 3 does not rely on a point estimate and, therefore, provides an information-gap model that is not generically equivalent to Wald's Maximin investment decision model. This implies that it escapes the harsh critique of Sniedovich $(2007$, p. 125$)$ that "the flaw in the Info-Gap uncertainty model"...."lies in the use of a single point estimate and its neighborhood as an approximation of an entire region of uncertainty." This expanded CML-based information-gap investment decision model allows for the exploration of thousands of investment opportunities, which dynamically "bubble up" in the average-returnuncertainty space of Markowitz.

\subsection{Comparative Value Analysis to Buy, Hold, or Sell}

We can now execute an information gap, $\left(1-\rho_{i M}^{2}\right)$, or robustness analysis by asking how much variation in the coefficient of determination $\rho_{i M}^{2}$ can occur and still produce an unambiguous investment or asset trading decision. What are the critical values for investment decision-making in the CAPM model? It is sometimes difficult to judge how much robustness is needed or sufficient, However, according to information gap theory (Ben-Haim, 2006), the ranking of feasible decisions in terms of their robustness is independent of such robustness judgments.

To provide a first indication, let's look at our empirical sector analysis in Figure 6. From 
our empirical sector analysis we know that, empirically, the information gap $\left(1-\rho_{i M}^{2}\right)$ in CAPM analysis is a substantial $85 \%-94 \%$. Since in our empirical example the market premium is $\left[E\left(r_{M}\right)-r_{F}\right]=5.91 \%-3.5 \%=2.41 \%$. This implies that for investment decisions, the CAPMdetermined investment hurdle rates can be between $85 \%-94 \%$ of the market risk premium of $2.41 \%$, or between $205-227$ basis points higher, i.e. considerably higher than conventionally computed!

\section{[PLACE FIGURE 6 ABOUT HERE]}

It can now also be explained why so many investors and stock traders "hold" stock, instead of buying or selling it. In the conventional biased textbook analysis, the "hold" decision does not exist (Cf. Ross, 1976), since the SML(1) is a razor-thin line. When an investor found an investment project or firm with an empirical average return $E\left(r_{i}\right)$ below it for a particular $\beta_{L}$, it was automatically deemed to have a too low average rate of return, i.e., it was too highly priced and therefore should be sold. The selling by investors or traders would drive the price down and its average return up, until it reached the $\operatorname{SML}(1)$. But market trading usually overshoots and we would find ourselves above $\operatorname{SML}(1)$, where investment $i$ would be deemed to have a too high average return, i.e., with a too low price. Ergo, it would be time to sell the stock. Thus, in the conventional textbook model at almost no time would any investor sit back and stop trading stock and just hold an investment. There would be only trading of investment assets or securities.

But that is not what we actually observe in the markets. Most investors buy and then hold stock for quite a while. Traders on both the buy-side and the sell-side face always two choices: to buy or to hold, respectively to sell or to hold. The information gap about an investment's risk premium earnings due to the Knightian uncertainty about what it's actual relative risk or $\beta$ is, cautions most investors and traders to make no rash decisions and to hold the stock for a while after buying or not to immediately buy it back after selling. As earlier noted, current empirical market risk premium uncertainty is between $205-227$ basis points wide or $85 \%-94 \%$ of the neutral market risk premium. 
This more realistic market situation can be illustrated in Figure 4 by looking at the three possible buy, hold and sell situations for aggressive, neutral defensive and undecided stocks. In other words, there are now $3 \times 3=9$ possible decision situations, instead of the four conventional SML(1) trading situations. The four conventional trading situations were the buying or selling of aggressive or defensive stocks.

Now, strictly speaking market-neutral stocks can only exist when $\rho_{i M}^{2}=\frac{\beta_{L}}{\beta_{U}}=1$. That situation occurs only on the CML and those Malkiel-recommended investments are strictly speaking not traded, but synthesized out of a linear combination of risk-free cash and an appropriate benchmarking market index, such as the S\&P500. Moreover, the dynamic portfolio replication theory of Black, Scholes and Merton is also based on such market-neutral, arbitrage free, linear combinations (using the call-put parity equation) and forms the basis of modern financial engineering of synthetic financial instruments of any kind. But as we have seen, such Knightian certainty situations are only reached post-arbitrage, but do not necessarily exist pre-arbitrage, thanks to Knightian uncertainty.

Any investment that has a market correlation different from unity, $\rho_{i M}^{2}=\frac{\beta_{L}}{\beta_{U}} \neq 1$, and thus experiences an uncertainty of risk premium, allows for arbitrage, i.e., trading, and, therefore, provides for "buy," "hold" and "sell" decisions. Thus model uncertainty is the "energy" for investment trading, since continuing regular arbitrage or trading cannot occur without some uncertainty about fair prices of existing stock or firm values. Without such uncertainty, one would engineer, manufacture or construct a desired investment portfolio with a particular average return and risk or $\left\{E\left(r_{i}\right), \sigma_{i}\right\}$ characteristic by a linear combination of cash and a market index and hold it forever. This would lead to a static and very stratified market society, since only inherited wealth would determine what investments would be constructed and they would all be engineered in exactly the same way for all times. That situation would also be extremely dangerous for any society, since it would be unable to adapt to a drastically changed environment.

But modern societies are dynamic merchant societies, i.e., arbitraging or regular trading so- 
cieties, which face uncertainties and use such uncertainties in a speculative or insurance fashion to become wealthy by profitable adaptation. The most fundamental societal uncertainty is created by innovations, i.e., new, marketable technological ideas that can be implemented, marketed and sold, because their value is initially very uncertain. Only by regular arbitrage of uncertain valuations, i.e., of trading their valuation uncertainty is eliminated and our information gap for valuation, $\left(1-\rho_{i M}^{2}\right)\left[E\left(r_{M}\right)-r_{F}\right]$ can be reduced.

\section{Valuation Uncertainty}

\subsection{Present Value Analysis of Growth Opportunities}

Smit and Trigeorgis (2004) show that long term strategic investment situations or real assets (factories, mines, office buildings, R\&D and other non-financial assets) may be valued as real options. Real options are situations where option theory is applied to value those very uncertain investment situations, which are common, for example, to biotech, pharmaceuticals, information technology, airline manufacturers, oil drilling, etc. One creatively develops Decision Tree Analysis (DTA) of such uncertain investments and then tries to asses the risks involved. Once such crude assessments are made to grow or to abandon or to operationally switch, existing neutral probability based option theory is used to value these complex strategic investments. Such corporate strategic planning and real option valuations can have substantial impacts on the market value of investment projects, firms and whole industrial sectors.

Real options analysis (often using binomial decision trees) is considered a big step beyond static valuation measures, such as price-earnings and price-to-book ratio analysis, although it is clear that it does not only involve subjective probabilistic risk assessments, but also Knightian uncertainty, which leads to incomparability of such idiosyncratic investment projects to traded assets. $^{9}$ In this section, we would like to focus on the impact of Knightian uncertainty in real

\footnotetext{
9 Indeed, the very assumption of comparability of investment projects is implied in the conventional assumption "that the returns of the project are spanned by existing traded assets; in other words, the addition of such a project to the universe of assets does not materially change the opportunities available to investors." (McDonald, 2006, p. 552, footnote 4). As McDonald (2006, p. 554) states: "....risk-neutral pricing and discounted cash flow
} 
options analysis, an impact that thus far has not been studied sufficiently in the financial literature.

Growth stocks typically yield high price-earnings and market-to-book ratios. "In fact, it is precisely the intangible and strategic value of growth opportunities that determines most of the market value of high-tech firms in a continuously changing environment;" and "There is indeed a clear appreciation in the market for a firm's bundle of corporate real options (present value or growth opportunities, or PVGO (Smit and Trigeorgis, 2004, p. 5; cf. their Figure 1.1 on p. 4).

We updated and expanded the exceedingly simple example of Table 1.1 of Smit and Trigeorgis (2004, p. 6), using our new understanding of the impact Knightian uncertainty has on investment valuation. We use this simplest possible corporate finance valuation model of a perpetuity as representative for a "long term" investment project. The Present Value of Growth Opportunities or $P V G O_{i}$ of firm $i$ is the difference between its market price per share $P_{i}$ and the intrinsic value of its first quarter economic earnings expectations $E_{i}^{1}$, or the intrinsic value of its static Net Present Value (NPV), appropriately discounted at the "hurdle" rate derived from the SML:

$$
P V G O_{i}=P_{i}-E_{i}^{1} / E\left(r_{i}\right)
$$

The expected first quarter economic earnings consist of cash payments and capital gains and may include growth expectations. When we express the $P V G O_{i}$ as a percentage of the firm's market price, we have

$$
\begin{aligned}
P V G O_{i} / P_{i} & =\left[P_{i}-E_{i}^{1} / E\left(r_{i}\right)\right] / P_{i} \\
& =1-\left(E_{i}^{1} / P_{i}\right) / E\left(r_{i}\right)
\end{aligned}
$$

Thus $P V G O_{i} / P_{i}$ is the remaining value in percentage of the share price, after comparison of first quarter earnings per share with the required "hurdle" rate of return. This explains why the of high hurdle rates in capital budgeting could be an approximate way to account for the present value of real options.

are alternative means of valuing a future cash flow." But the essence of strategic investments is their idiosyncratic nature of adding a new and profitable comparative advantage to the existing investment universe. The idiosyncratic nature of strategic investments makes comparability non-existing, per definition. 
Our preceding CAPM based SML - hurdle rate analysis, which takes account of Knightian uncertainty, leads to an uncertainty range of "hurdle" rates,, because of the information gap:

$$
E\left(r_{i}\right)_{S M L(1)} \leq E\left(r_{i}\right) \leq E\left(r_{i}\right)_{S M L(2)}
$$

We saw that, based on our empirical sector analysis, that the information gap of hurdle rates $\left[E\left(r_{i}\right)_{S M L(2)}-E\left(r_{i}\right)_{S M L(1)}\right]$ is between $205-227$ basis points wide. Consequently, there must exist considerable valuation uncertainty about the present value of growth opportunities in firms and industries:

$$
\left(P V G O_{i} / P_{i}\right)_{S M L(1)} \leq P V G O / P \leq\left(P V G O_{i} / P_{i}\right)_{S M L(2)}
$$

Indeed, when we applied this investment decision-making technology to 1, 050 firms of Morningstar's Principia STOCKS ADVANCED database as of December 2007, which could be matched with one-quarter ahead IBES-projected earnings per share from the COMPUSTAT data base as of December 2007, we found considerable $P V G O / P$ valuation uncertainty. As an illustration, we summarize in the following Table 3 average industry sector results corresponding with Table 1.1 in Smit and Trigeorgis (2004, p. 6). According to Table 3, the uncertainty gap of PVGO percentages, $\left.\left.\left[P V G O_{i} / P_{i}\right)_{S M L(2)}-P V G O_{i} / P_{i}\right)_{S M L(1)}\right]$, varies between 25 and 481 basis points depending on the industry sector.

\section{[PLACE TABLE 3 ABOUT HERE]}

Because of this valuation uncertainty due to the Knightian uncertainty gap, the average $P V G O / P$ is not as certain as real option theorists may want us believe (See, for example, McDonald, 2006, Chapter 17 "Real Options." See also Trigeorgis, 1998, and Amran and Kulatilaka, 1999), because real option theory is based on the existential comparability of traded assets. But strategic long term investment projects have a very high idiosyncratic component. This paper emphasizes that even when risk is somehow measured, our Knightian uncertainty gap often prevents risk from being well-measured, because of a low degree of information determination, i.e. a low quality of the available information. 
Comparing the empirical sector results of Table 2 and Table 4 it is rather striking that the industry sectors with the highest levels of idiosyncratic risk appear to correspond with the industrial sectors with the widest range of valuation uncertainty regarding the percentage of the market price representing the present value of future growth opportunities, in particular utilities, telecommunications and software. This appears to be in line with the general observation of Figure 3A, which informs us, first, that, indeed, the sectors with the highest average returns are the ones with the highest levels of measurable risk, but, second, that the ones that have more idiosyncratic risk (lying on a lower market correlation "beam" in Fig. 3) have a relatively lower average rate of return for the same level of risk.

Again, is no surprise that advanced multivariate options, like quantos (for example, equitylinked currency options, or currency linked equity options), crucially depend on their so-called correlation risk $\rho_{i j}$, which expresses Knightian uncertainty, and that occurs already for comparable,traded assets, for which we have existing pricing processes. The tailing dividend yield of the underlying, being it of another equity $\left(\delta_{j}\right)$ or another currency $\left(r_{j}\right)$, must be reduced by the covariance risk $\rho_{i j} \sigma_{i} \sigma_{j}$ to effectuate an appropriate change in numéraire for the standard BlackScholes call formula. Of course, for strategic, highly idiosyncratic, investment projects we lack even that comparability information.

A note of caution is in order, since this paper assumed wide-sense stationarity of the returns on investments, so that their relative investment position can be measured by their position in Markowtz two-parameter average return-risk space . Option theory may be able to fairly (if not necessarily arbitrage-freely) value investment assets using risk-neutral probabilities derived from replicating portfolios, even when literal replication of the option is not possible, because the twin security does not exist. But this is true only when the return volatility or risk is well-defined and well-measured by the standard deviation of returns $\sigma_{i}$ of a possible underlying asset. The usual presumption of log-normally distributed asset prices presumes the existence of constant limited and not of an infinite volatility. The presumption of ergodicity in general, in particular, of wide- 
sense stationarity of the rate of return distributions, is essential to modern option pricing. But that presumption maybe based on an illusion, and heavily tinted by our ignorance of the true workings of the financial markets, i.e., by our lack of fundamental empirical information about the markets. To view a firm as a perpetual call option to be valued by using perpetual call option formulas may the biggest investment valuation illusion of them all.

Indeed, both the economist and "fractal" mathematician Mandelbrot (1966) and, more recently, the famous option-trader Taleb (2007) have already warned us about financial market hubris and the possibility of infinite variance, which may result in many previously unrecognized and undetected "black swans." The possible existence of infinite variance implies the possible existence of infinite Knightian uncertainty. It is, again, not surprising that the study of market "crashes" has recently taken extra quantified flight (Cf. , for example, Sornette 2003). This "illusion of empirical market knowledge," based on the assumed geometric Brownian motion price diffusion processes, is now a topic of considerable concern to financial economists and financial risk managers. We've already urged investors to empirically measure uncertainty in a different, non-probabilistic, fashion and to adjust option valuation theory accordingly (Los, 2003; Elliott and Van Der Hoek, 2001; Jamdee and Los, 2007).

\section{Conclusions}

In his 1921 book on Risk, Uncertainty and Profit the Chicago economist Frank H. Knight gave special consideration to dynamic and risk theories. Knight stated that

"The former confuses the effects of change with those of the uncertainty connected with change - The latter falls into confusion failing to distinguish between risk in the sense of a measurable probability and an uncertainty which cannot be measured Change according to a known law does not give rise to profit, nor does risk if measurable, since it can be eliminated by insurance or some equivalent device." (= Knight's own summary of his Chapter II, Theories of Profit: Change and Risk in Relation to 
Profit, Knight, 2006, pp. 22 -48)

His statement still rings true: known dynamics and measurable probability can be arbitraged away and hedged (insured), respectively, as applications of modern option theory clearly prove. But it is also important to recognize that only unmeasurable and thus uninsurable Knightian uncertainty gives rise to profit. Options pricing based on probability-measurable risk helps to insure against that risk. Knightian uncertainty can only be reduced by advancements in knowledge. Such possible advancements in knowledge are driven by R\&D financed out of the profits generated by profitable idiosyncratic investment projects. That is called "venture capitalism." It is the only way to raise humankind's living standards in a sustainable fashion. All other societal system proposals have historically failed.

In this paper the most important notion is that of Knightian epistemological uncertainty or "model uncertainty." The paper demonstrates that the allocation of total investment risk over measurable, and thus insurable, market risk and idiosyncratic (firm-specific) risk crucially depends on this model uncertainty. Model uncertainty does not distort the conventional Capital Market Line based and concomitant Sharpe Ratio analysis, since all investment choices in Markowitz' mean return - risk space can be immediately affiliated with their appropriate investment Sharpe Ratios, which are multiples of the market's Sharpe Ratio, or slope of the Capital Market Line (CML). Their respective multipliers are uniquely measured by the corresponding market correlation coefficients $\rho_{i j}$

But model uncertainty causes problems within Sharpe's mean return - beta space in which the Security Market Lines (SML) reside, since the beta $\beta$ is no longer uniquely measured. Galton's Error clearly shows that there is a $\beta$-range. The relative size of that range of $\beta$-measurability is determined by the information gap $\left(=1-\rho_{i j}^{2}=\right.$ percentage of non-determination). This same information gap measures the uncertainty range of the risk premium of an investment, which makes the usual SML analysis and accompanying arbitrage pricing arguments less simple and 
much more complex. In a more advanced option analysis context, Knightian uncertainty also reduces the certainty of the usual Present Value of Growth Opportunity analysis used in Real Options analysis.

However, the expansion of the conventional investment analysis in this paper helps to explain not only why, in addition to the usual analytical categories of "aggressive," "neutral" and "defensive" investments and firms, we have a category "undecided" and why financial analysts often remain undecided regarding their recommendations. More importantly, perhaps, it finally explains, in a textbook fashion, why investors and traders receive "hold" signals in addition to binomial "buy" and "sell" signals and why investments are "held" and not immediately and continuously traded (arbitraged) by investors.

Moreover, the existence of model uncertainty also explains why it is difficult for the SEC to obtain a market consensus regarding what constitutes firm risk and what constitutes "fair pricing," let alone arbitrage-free pricing. For arbitrage-free pricing to be complete, model uncertainty should not exist. But it does empirically exist, because investment analysts do not possess infinite knowledge. Empirically well-founded scientific knowledge is more limited and scarce than generally assumed, in particular by economists, and therefore very valuable (Los, 1991). Asset markets are incomplete because of lack of such scarce knowledge. Not every new investment opportunity is spanned by existing investment opportunities. If it were, it could be completely analyzed by Wald's Maximin models, like Markowitz portfolio selection by maximin optimization. The fundamental incompleteness of investment knowledge - information gaps - prevents that. True innovations cause unique, or idiosyncratic, investment valuation "noise" that is unexplainable, and is not spanned by existing investment alternatives. It is this investment model uncertainty that attracts true speculators and that ultimately generates the true "profit" that helps to raise living standards in the world.

The most fundamental investment uncertainty is created by those idiosyncratic innovations, i.e. new, potentially marketable, technological ideas that may be implemented, marketed and sold. 
Only "maybe," because their investment value is initially very uncertain, as our example of various industry sectors clearly shows. Only by regular analysis and trading of their uncertain valuations, i.e., by increasing investment knowledge, their valuation uncertainty, may be, gradually eliminated and their information gap of valuation $\left(1-\rho_{i M}^{2}\right)\left[E\left(r_{M}\right)-r_{F}\right]$ reduced. But this is not necessarily so, since new knowledge also increases our awareness of new risks and uncertainties, e.g., pollution and other expensive environmental risks. New knowledge broadens our perspective, but it also simultaneously replaces old knowledge. Alternative investment opportunities replace older ones and the investment "scatter" in Markowitz average return-risk space is not necessarily reduced. New investments continue to "bubble up" and "bubble down" in that investment opportunity space. Schumpeter was the academic observer and defining scholar of this innovation process and Drucker was the business consultant who designed and prescribed management styles to harnass it (Schumpeter, 1949; McGraw, 2007; Drucker and Maciariello, 2008). Schumpeter and Drucker were both very well aware that this "bubbling" innovation process is the essential, but unsettling, wealth-enhancing component of market-based capitalism.

As Frank Knight already presaged, it is for this reason - the continued generation of new knowledge and of changes in model uncertainty - that this technological noise and its accompanying model uncertainty pervades the real world of Corporate Finance, Portfolio Management and Real Option valuations and cannot be completely eliminated. In fact, it is the fundamental energy that drives the creation and continuation of markets. But financial economists have been reluctant to acknowledge the existence of Knightian model uncertainty in their textbook examples, due to their ambiguity aversion. Now that global investment managers are facing many globally interdependent multi-variate investments which are rapidly declining in value, it is urgent to incorporate this model uncertainty into investment decision-making and to acknowledge its pervasive existence and potential profitability for those who understand such model risk. 


\section{References}

Allais, M. (1953) "Le Comportement de l'Homme Rational Devant le Risque: Critique des Postulats et Axioms de l'Ecole Americaine," Econometrica, 21, 503-546.

Amran, Martha and Nalin Kulatilaka (1999) Real Options: Managing Strategic Investment in an Uncertain World, Harvard Business School Press, Boston, MA.

Ben-Haim, Yakov (2004) "Uncertainty, Probability and Information-Gaps," Reliability Engineering and System Safety, 85, 249-266.

Ben-Haim, Yakov (2005) "Value at Risk with Info-Gap Uncertainty, Journal of Risk Finance, 6-5, 388-403.

Ben-Haim, Yakov (2006) Info-Gap Decision Theory: Decisions Under Severe Uncertainty, 2nd ed., Elsevier, Amsterdam. (original 2001).

Beresford-Smith, Bryan, and Colin J. Thompson (2007) "Managing Credit Risk with Info-Gap Uncertainty," The Journal of Risk Finance, 8-1, 24-34.

Bernstein, Peter (1996) Against the Gods: The Remarkable Story of Risk, John Wiley \& Sons, New York, NY

Bodie, Zvi, Alex Kane and Alan J. Marcus (1999) Investments, 4th ed., Irwin McGraw-Hill, Boston, MA.

Das, Satyajit (2006) Traders, Guns 83 Money: Knowns and Unknowns in the Dazzling World of Derivatives, Financial Times/T Prentice Hall.

Dixit, Avinash K. and Robert S. Pindyck (1994) Investment Under Uncertainty, Princeton University Press, Princeton, NJ.

Drucker, Peter F., and Joseph A. Maciariello (2008) Management, rev. ed., Collins, New York, NY (original 1973).

Elliott, Robert J., and John Van der Hoek (2003) "A General Fractional White Noise Theory and Applications to Finance," Mathematical Finance, 13, 301 - 330. 
Ellsberg, D. (1961) "Risk, Ambiguity, and the Savage Axioms," Quarterly Journal of Economics, $\mathbf{7 5}, 641-669$.

Haugen, Robert A. (2001) Modern Investment Theory, 5th ed.,Prentice Hall, Upper Saddle River, NJ.

Hughes, Jennifer, Francesco Guerrera and Joanna Chung (2008) "SEC Fails to Douse Debate Over "Fair Value," Financial Times (www.ft.com), March 31.

Jamdee, Sutthisit, and Cornelis A. Los (2007) "Long Memory Options: LM Evidence and Simulations," Research in International Business and Finance, 21, 260-280.

Keynes, John Maynard (1921) A Treatise on Probability, Macmillan, London, UK.

Knight, Frank H. (2006) Risk, Uncertainty and Profit, Dover Publications, Mineola, NY (original 1921).

Lintner, John (1965) "The Valuation of Risk Assets and the Selection of Risky Investments in Stock Portfolios and Capital Budgets," Review of Economics and Statistics, 47-1, February, $13-37$.

Los, Cornelis A. (1991) "A Scientific View of Economic Data Analysis," Eastern Economic Journal, 17-1, January/March, 1991, 61 - 71.

Los, Cornelis A. (1999) "Galton's Error and the Under-Representation of Systematic Risk," Journal of Banking and Finance, 23, 1793 - 1829.

Los, Cornelis A. (2003) Financial Market Risk: Measurement and Analysis, Routledge/Taylor \& Francis Group, London, UK.

Los, Cornelis A. (2006) "System Identification in Noisy Data Environments: An Application to Six Asian Stock Markets," Journal of Banking and Finance, 30, 1997-2024.

Malkiel, Burton (1990) A Random Walk Down Wall Street, 5th ed., W. W. Norton \& Co., New York, NY (original 1973).

Markowitz, Harry, M. (1952) "Portfolio Selection," Journal of Finance, March, 7-1, 77-91.

Markowitz, Harry, M. (1987) Mean-Variance Analysis in Portfolio Choice and Capital Markets, 
Basil Blackwell, New York, NY.

Markowitz, Harry, M. (1991) Portfolio Selection: Efficient Diversification, Basil Blackwell, Cambridge, MA. (original 1959).

McDonald, Robert L. (2000) "Real Options and Rules of Thumb in Capital Budgeting," in Brennan, M. J. and L. Trigeorgis (Eds) Project Flexibility, Agency, and Competition: New Developments in the Theory and Applications of Real Options, Oxford University Press, London, UK, Chapter 2, pp. $13-33$.

McDonald, Robert, L. (2006) Derivatives Markets, 2nd ed, Addison Wesley, Boston, MA.

McGraw, Thomas K. (2007) Prophet of Innovation: Joseph Schumpeter and Creative Destruction, Belknap Press of Harvard University Press, Cambridge, MA.

Mossin, Jan (1966) "Equilibrium in a Capital Asset Market," Econometrica, October, 34-4, 768-783.

Ross, S. A. (1976) "The Arbitrage Theory of Capital Asset Pricing," Journal of Economic Theory, 13, 341-360.

Sales, Robert (2008) "Seeking Answers in Volatile Times: The Burden of Uncertainty," GARP Risk Review, March/April, p. 1.

Schumpeter, Joseph A. (1949) Science and Ideology, The American Economic Review, 39-2, March, 346-359.

Shackle, G. L. S. (1972) Epistemics and Economics: A Critique of Economic Doctrines, Transaction Publishers, New Brunswick, NJ, 1992 (original, 1972).

Sharpe, William (1964) "Capital Asset Prices: A Theory of Market Equilibrium Under Conditions of Risk," Journal of Finance, September, 19-3, 425-442.

Sharpe, William F. (1970) Portfolio Theory and Capital Markets, McGraw-Hill, New York, NY.

Smit, Han, T. J. and Lenos Trigeorgis (2004), Strategic Investment: Real Options and Games, Princeton University Press, Princeton and Oxford. 
Sniedovich, M. (2007) "The Art and Science of Modeling Decision-Making Under Severe Uncertainty," Decision-Making in Manufacturing and Services, 1, 1-2, 111-136.

Sornette, Didier (2003) Why Stock Markets Crash: Critical Events in Complex Financial Systems, Princeton University Press, Princeton, NJ.

Taleb, Nassim N. (2006) The Black Swan: The Impact of the Highly Improbable, Random House, New York, NY.

Tobin, James (1958) "Liquidity Preference as Behavior Towards Risk," Review of Economic Studies, February, 25, 65-86.

Trigeorgis, Lenos (1998) Real Options: Managerial Flexibility and Strategy in Resource Allocation, The MIT Press, Cambridge, MA.

Wald, Abraham (1945) "Statistical Decision Functions Which Minimize the Maximum Risk," The Annals of Mathematics, 46-2, 265 - 280.

Wald, Abraham (1950) Statistical Decision Functions, John Wiley \& Sons, Inc., New York,NY. 


\section{Tables}

Table 1: Systematic Risk Categorization of Mutual Funds in 1995 and 2007

Table 2: Ranking of Industries According to Their Percentages of Idiosyncratic (Industrial Sector) Risk

Table 3.: Ranking of Industries According to The Valuation Uncertainty of Their PVGO/P Ratios

\section{Figures}

Fig. 1: Galton's Error and the Empirical Information Gap

Fig. 2: The Certain Capital Market Line (CML) and the Uncertain Security Market Line $(\mathrm{SML})$

Fig. 3: Certain Capital Market Line and Idiosyncratic Risk: Theory

Fig. 4: Certain Capital Market Line and Idiosyncratic Risk: Empirical Example of Sector Analysis

Fig. 5: Uncertainty of Risk Premia, CAPM and Buy, Hold, and Sell Signals: Theory

Fig. 6: Uncertainty of Risk Premia, CAPM and Buy, Hold, and Sell Signals: Empirical Sector Analysis 
Figure 1: Table 1: Systematic Risk Categorization of Mutual Funds in 1995 and 2007

\begin{tabular}{cccc}
\multicolumn{1}{c}{$1995^{*}$} & \multicolumn{2}{c}{2007} \\
$\#$ & $\%$ & $\#$ & $\%$ \\
7051 & & 20340 \\
3227 & & 16550 \\
3215 & & 16354
\end{tabular}

4. According to AIMR (CFA) Performance Presentation Standards, 1993, 1996:

(i) Defensive funds: $0<\beta_{\mathrm{L}}<1$

(ii) Neutral, market index funds: $\beta_{\mathrm{L}}=1$

(iii) Aggressive funds: $1<\beta_{\mathrm{L}}$

Total funds with measurable market risk

$\begin{array}{rrrc}2047 & 63.7 & 7053 & 43.1 \\ 67 & 2.1 & 517 & 3.2 \\ 1101 & 34.2 & 8784 & 53.7 \\ 3215 & 100.0 & 16354 & 100.0\end{array}$

5. According to Kalman/Los Complete Least Squares (CLS) analysis

(i) Defensive funds: $0<\beta_{L}$ ? $\beta_{U}<1$

(ii) Neutral, market index funds: $\beta_{\mathrm{L}}=\beta_{\mathrm{U}}=1$

(iii) Aggressive funds: $1<\beta_{L}$ ? $\beta_{U}$

(iv) Undecided: $0<\beta_{\mathrm{L}}<1<\beta_{\mathrm{U}}$

Total funds with measurable market risk
608

18

1101

1488

321

18.9

0.6

34.2

46.3

3496

174

9127

3557

21.4

1.1

55.8

21.7

$6354 \quad 100.0$

- Source: Los, Cornelis A., Galton's Error and the under-representation of systematic risk, Journal of Banking and Finance, 23, 1999, 1793-1829: Table 2 on page 1815

Figure 2: Table 2: Ranking of Industries According to Their Percentages of Idiosyncratic (Industrial Sector) Risk

\begin{tabular}{|c|c|c|c|c|c|}
\hline \multirow[b]{3}{*}{ Sector } & \multicolumn{3}{|c|}{ Risk \% } & \multicolumn{2}{|c|}{ Risk \% Ratios } \\
\hline & Total Risk & Firm Risk & Market Risk & Firm/Total & Market/Total \\
\hline & $(1)=(2)+(3)$ & $(2)$ & (3) & $(4)=(2) /(1)$ & $(5)=(3) /(1)$ \\
\hline Utilities & 4.8 & 4.5 & 0.3 & 0.938 & 0.063 \\
\hline Healthcare & 21.1 & 19.4 & 1.7 & 0.919 & 0.081 \\
\hline Telecommunications & 22.9 & 20.7 & 2.2 & 0.904 & 0.096 \\
\hline Software & 16.3 & 14.6 & 1.6 & 0.896 & 0.098 \\
\hline Energy & 12.3 & 11.0 & 1.3 & 0.894 & 0.106 \\
\hline Business Services & 14.3 & 12.8 & 1.5 & 0.894 & 0.106 \\
\hline Hardware & 27.6 & 24.5 & 3.1 & 0.888 & 0.112 \\
\hline Consumer Services & 13.1 & 11.5 & 1.7 & 0.878 & 0.130 \\
\hline Industrial Materials & 14.4 & 12.6 & 1.8 & 0.875 & 0.125 \\
\hline Consumer Goods & 11.0 & 9.6 & 1.3 & 0.873 & 0.118 \\
\hline Media & 10.4 & 8.9 & 1.4 & 0.856 & 0.135 \\
\hline Financial Services & 6.7 & 5.7 & 1.0 & 0.851 & 0.149 \\
\hline
\end{tabular}


Figure 3: Table 3.: Ranking of Industries According to The Valuation Uncertainty of Their $\mathrm{PVGO} / \mathrm{P}$ Ratios

\begin{tabular}{|l|c|c|c|c|}
\hline & \multicolumn{3}{|c|}{ Average PVGO/P (IBES-based) } \\
\hline \multirow{2}{*}{ Sector } & Using $\boldsymbol{\beta}_{\mathrm{L}}$ & Using $\boldsymbol{\beta}_{\mathrm{U}}$ & Value Uncertainty \\
\cline { 2 - 5 } & $\mathbf{( 1 )}$ & $\mathbf{( 2 )}$ & $\mathbf{( 3 ) = ( 2 ) - ( \mathbf { 1 } )}$ \\
\hline Telecommuncations & & & \\
Software & -3.93 & 0.88 & $\mathbf{4 . 8 1}$ \\
Media & -3.41 & 0.89 & $\mathbf{4 . 3 0}$ \\
Utilities & -1.74 & 0.87 & $\mathbf{2 . 6 1}$ \\
\hline Business Services & -0.89 & 0.90 & $\mathbf{1 . 7 9}$ \\
Consumer Goods & 0.23 & 0.95 & 0.72 \\
Financial Services & 0.35 & 0.94 & 0.59 \\
Consumer Services & 0.38 & 0.92 & 0.54 \\
Healthcare & 0.42 & 0.88 & 0.46 \\
Energy & 0.63 & 0.95 & 0.32 \\
Hardware & 0.68 & 0.97 & 0.29 \\
Industrial Materials & 0.69 & 0.95 & 0.26 \\
& 0.71 & 0.96 & 0.25 \\
\hline
\end{tabular}


Figure 4: Fig. 1: Galton's Error and the Empirical Information Gap

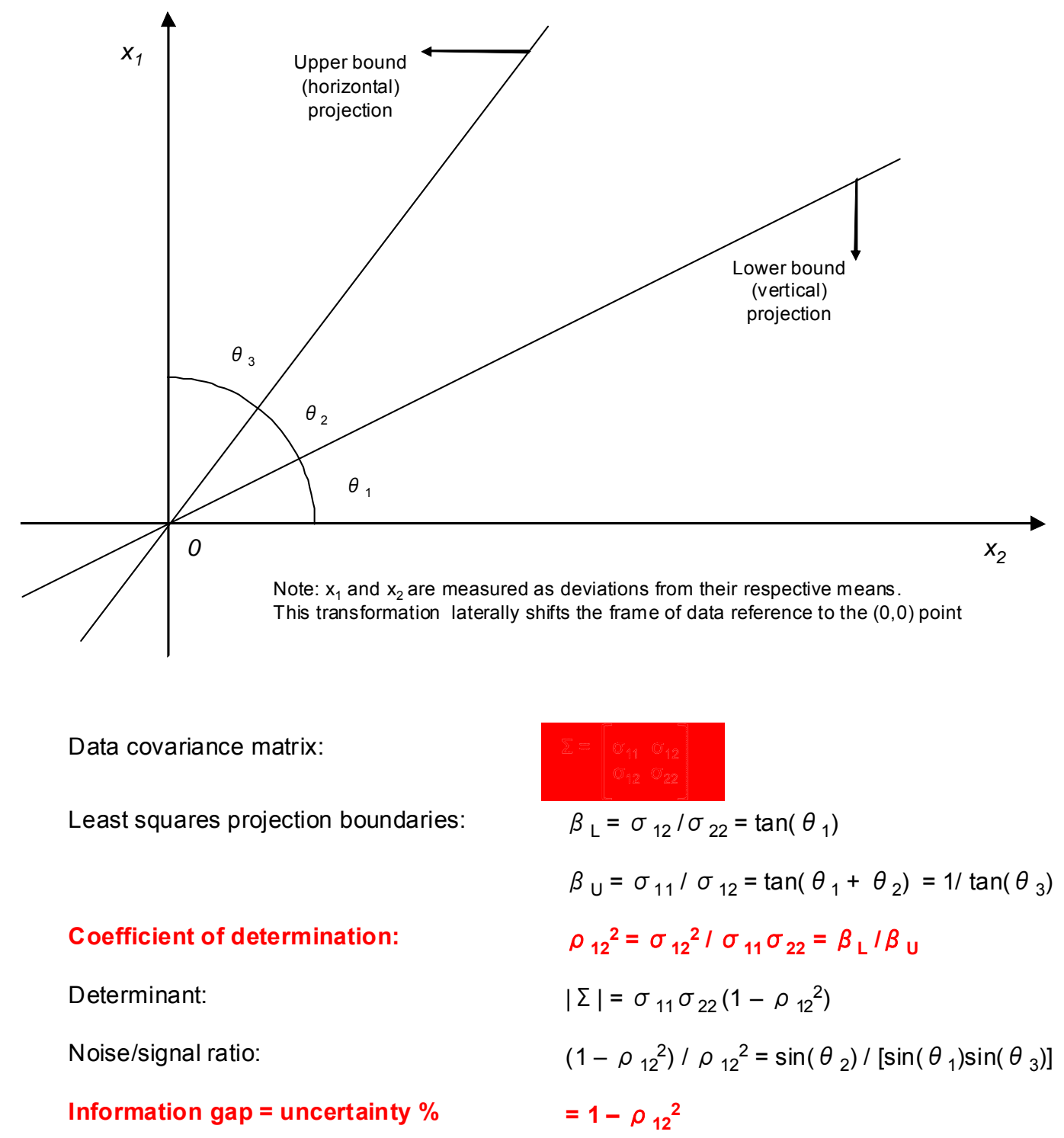


Figure 5: Fig 2. The Certain Capital Market Line (CML) and the Uncertain Security Market Line (SML)

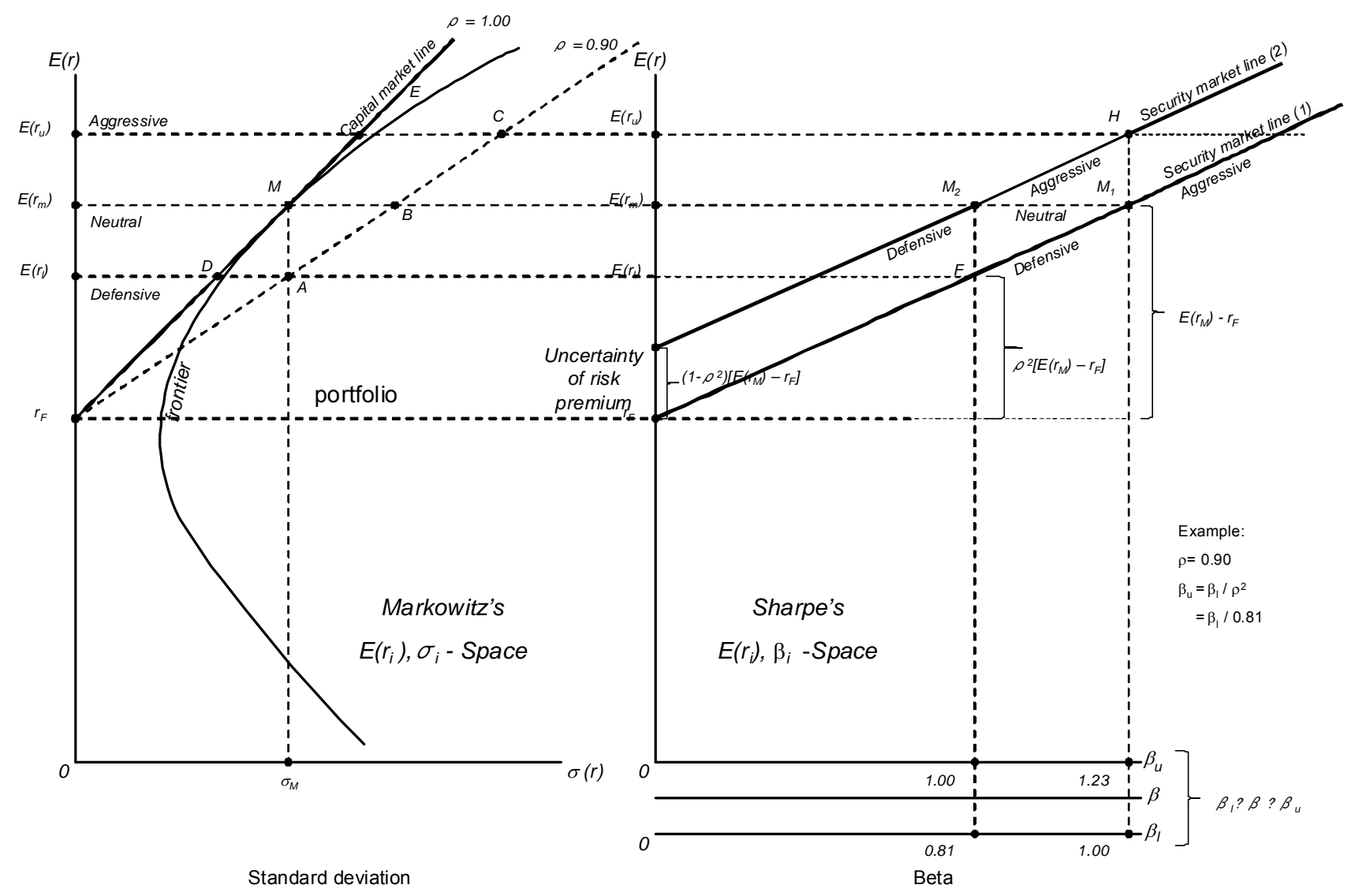


Figure 6: Fig 3. Certain Capital Market Line and Idiosyncratic Risk: Theory

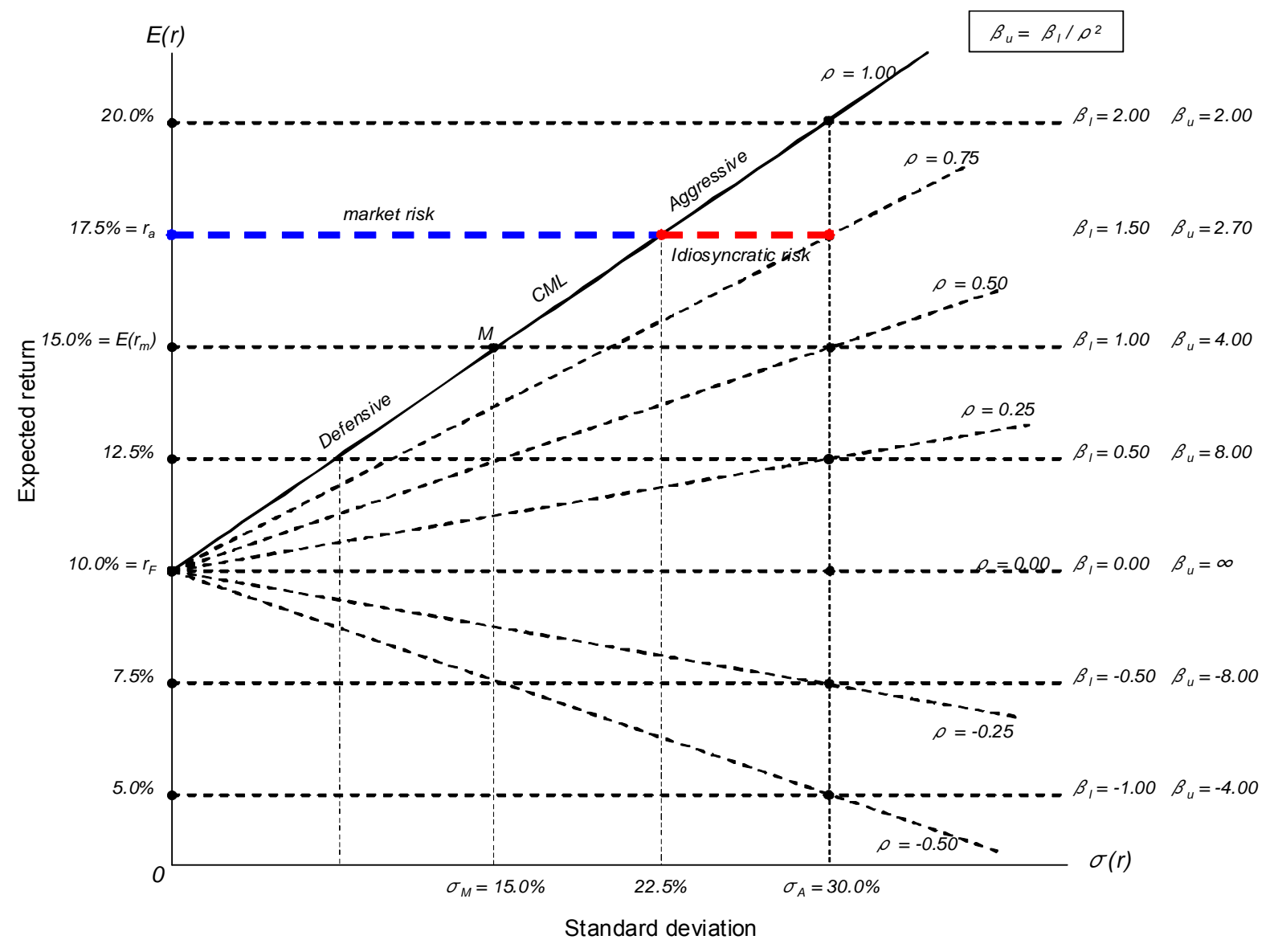


Figure 7: Fig 4.: Certain Capital Market Line and Idiosyncratic Risk: Empirical Example of Sector Analysis

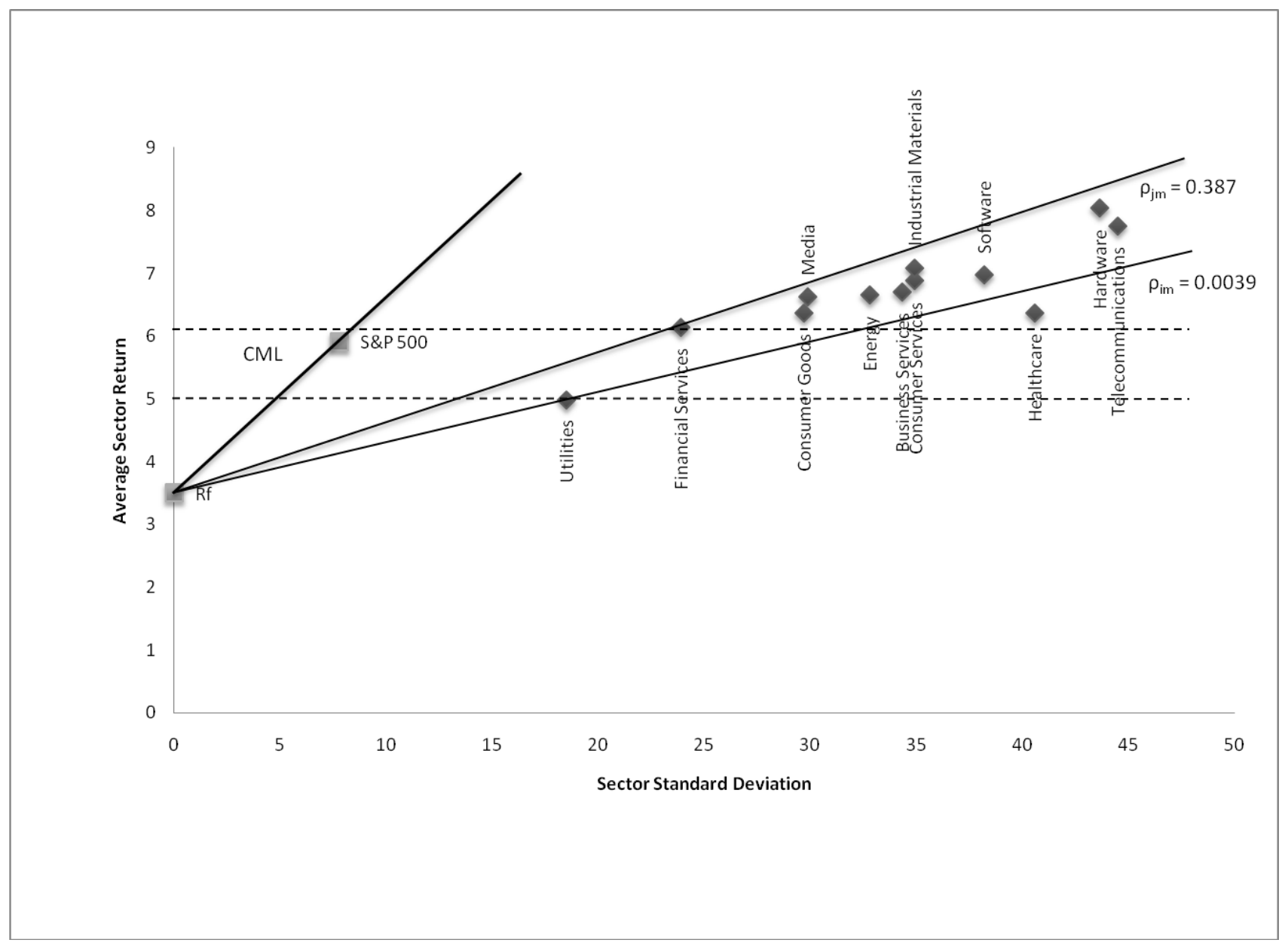

Figure 8: 
Figure 9: Fig 5. Uncertainty of Risk Premia, CAPM and Buy, Hold, and Sell Signals: Theory

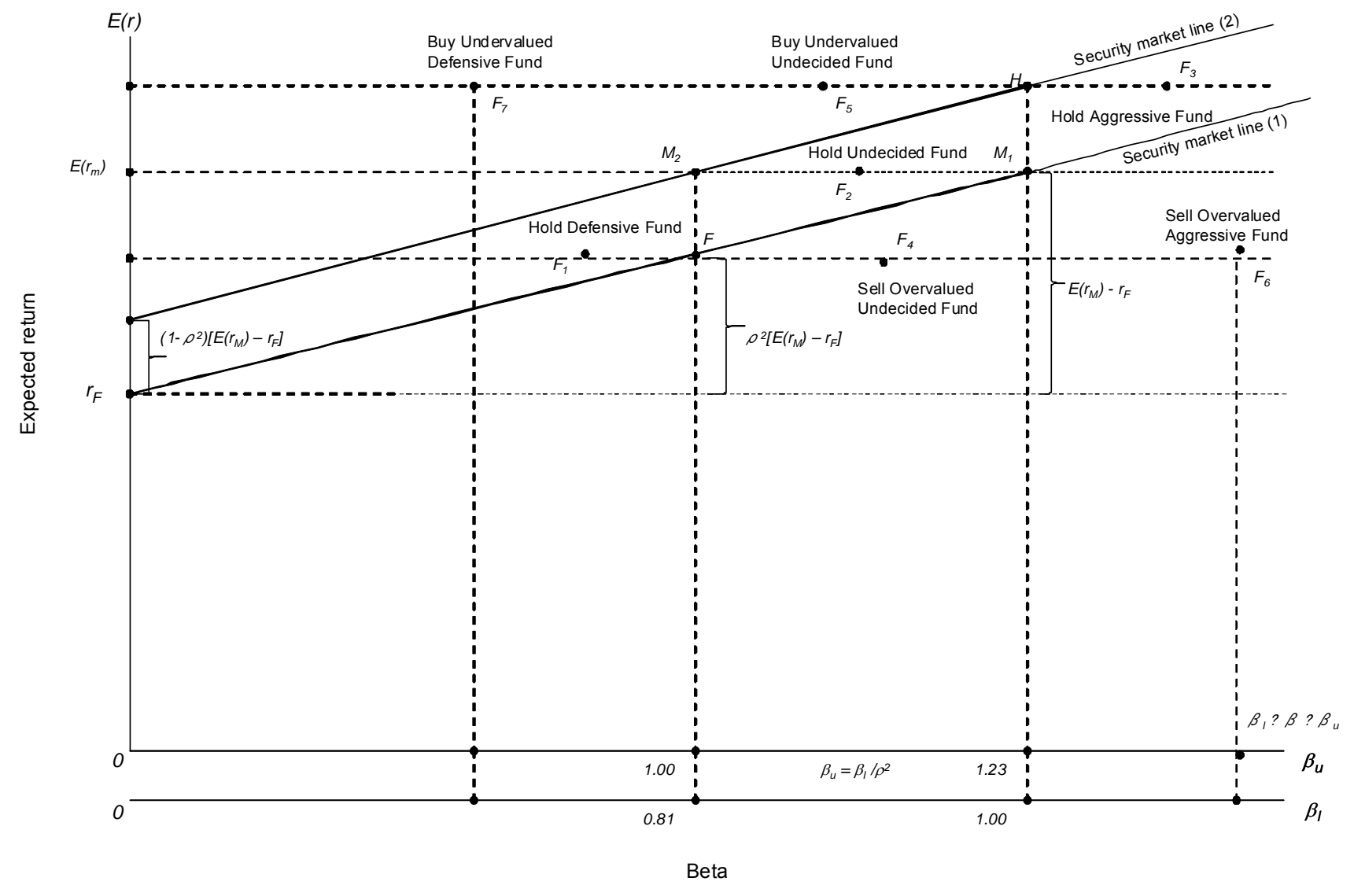


Figure 10: Fig. 6: Uncertainty of Risk Premia, CAPM and Buy, Hold, and Sell Signals: Empirical Sector Analysis

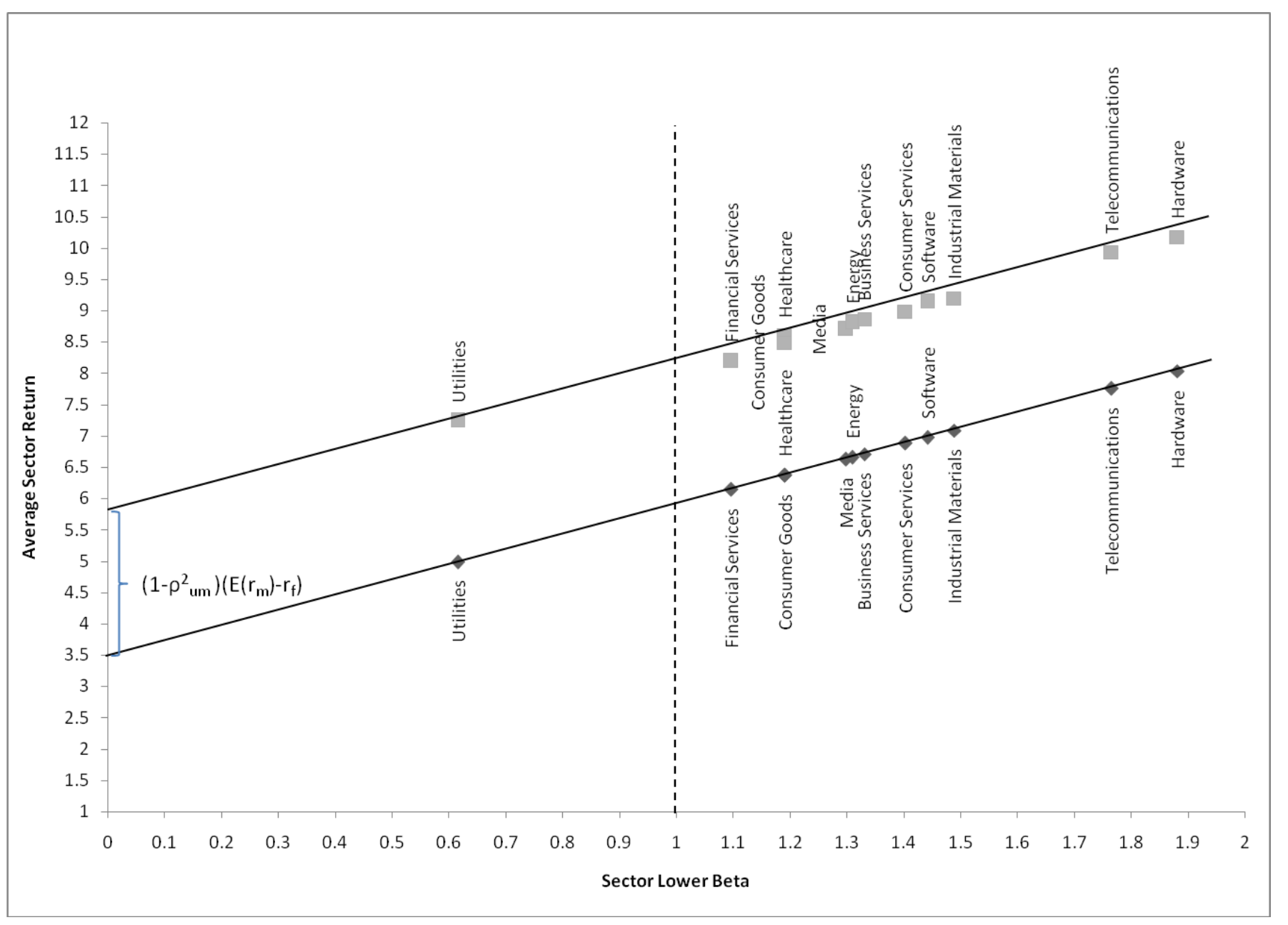

Figure 11: 